Climate Dynamics

October 2016, Volume 47, Issues 7-8, Pages 2309-2330

http://dx.doi.org/10.1007/s00382-015-2965-7

http://archimer.ifremer.fr/doc/00334/44480/

(c) Springer-Verlag Berlin Heidelberg 2016

\title{
Mesoscale SST-wind stress coupling in the Peru-Chile current system: Which mechanisms drive its seasonal variability?
}

\author{
Oerder Vera ${ }^{1}$, , Colas François ${ }^{1}$, Echevin Vincent ${ }^{1}$, Masson Sebastien ${ }^{1}$, Hourdin Christophe ${ }^{1}$, \\ Jullien Swen ${ }^{1,2}$, Madec Gurvan ${ }^{1,3}$, Lemarié Florian ${ }^{4}$
}

${ }^{1}$ LOCEAN-IPSL, CNRS/IRD/UPMC, UMR7159, Paris, France

${ }^{2}$ LOS, IFREMER, Plouzané, France

${ }^{3}$ National Oceanography Centre, Southampton, Marine Systems Modelling Group, European Way, Southampton, SO14 3ZH, UK

${ }^{4}$ INRIA, Université Grenoble Alpes, CNRS, LJK, 38000, Grenoble, France

*Corresponding author : Vera Oerder, email addresses : volod"@locean-ipsl.upmc.fr ; vera.oerder@locean-ipsl.upmc.fr

\begin{abstract}
:
Satellite observations and a high-resolution regional ocean-atmosphere coupled model are used to study the air/sea interactions at the oceanic mesoscale in the Peru-Chile upwelling current system. Coupling between mesoscale sea surface temperature (SST) and wind stress (WS) intensity is evidenced and characterized by correlations and regression coefficients. Both the model and the observations display similar spatial and seasonal variability of the coupling characteristics that are stronger off Peru than off Northern Chile, in relation with stronger wind mean speed and steadiness. The coupling is also more intense during winter than during summer in both regions. It is shown that WS intensity anomalies due to SST anomalies are mainly forced by mixing coefficient anomalies and partially compensated by wind shear anomalies. A momentum balance analysis shows that wind speed anomalies are created by stress shear anomalies. Near-surface pressure gradient anomalies have a negligible contribution because of the back-pressure effect related to the air temperature inversion. As mixing coefficients are mainly unchanged between summer and winter, the stronger coupling in winter is due to the enhanced large-scale wind shear that enables a more efficient action of the turbulent stress perturbations. This mechanism is robust as it does not depend on the choice of planetary boundary layer parameterization.
\end{abstract}

Keywords : Ocean-atmosphere interactions, Mesoscale SST-wind stress coupling, Regional coupled modeling, Eastern Boundary Upwelling System 


\section{Introduction}

Surface Wind Stress (WS) is one of the main forcing of the ocean dynamics. Coarse spatial resolution sea surface temperature (SST) and WS intensity fields present negative correlations (Liu et al, 1994; Xie, 2004), characteristic of an ocean driven by the atmosphere : more intense WS cools the surface water through evaporation and entrainment of subsurface water in the mixed layer. However, higher resolution fields contain mesoscale structures ( $\sim 10$ to $100 \mathrm{~km}$, scales corresponding to the oceanic mesoscale) that show a contrasting behavior. SST-WS intensity correlations are positive under the effect of the ocean feedback on the atmosphere (Small et al, 2008). The atmospheric response to the SST was first observed by Sweet et al (1981) above the north wall of the Gulf Stream. A cross-front WS intensity increase was detected when passing from cold to warm waters. Further observational campaigns (Businger and Shaw, 1984; Giordani et al, 1998) in other regions also evidenced enhanced (weakened) WS intensity over warmer (colder, respectively) SST. Then, satellite data confirmed this result (Chelton et al, 2001; Bourras et al, 2004) and a proportional relationship between WS intensity and SST mesoscale anomalies has been identified (e.g. O'Neill et al, 2010) :

$$
\left\|\overrightarrow{\tau_{s}}\right\|^{\prime} \propto S S T^{\prime}
$$

Wit the r O'Neill et al, 2010). A concurrent relation between SST laplacian and the near-surface wind speed divergence has been proposed by Minobe et al (2008), assuming the surface wind speed to be proportional to the WS. In this case, the WS divergence is proportional to the SST Laplacian (and not to the downwind SST gradient). In the present work we focus on relation (1) because it shows the strongest correlations in our region of interest. A comparison between the two types of SST-WS interactions is presented in the discussion (Sec. 5.3). 
As recently underlined by Byrne et al (2015), the mechanisms leading to SST and WS intensity correlated patterns remain unclear and various processes have been proposed to explain (1). In the atmospheric Planetary Boundary Layer (PBL), the turbulent vertical mixing of momentum can be parameterized by a turbulent stress $\vec{\tau}$. WS is the boundary condition of the turbulent stress at the air/sea interface. Samelson et al (2006) relate WS to the turbulent stress vertical shear and the PBL height, defined as the height above which $\vec{\tau}$ vanishes. Under the strong assumption of an unchanged vertical stress shear, a PBL height increase above warm waters would result in a WS intensity increase. SST mesoscale anomalies could also affect the pressure in the PBL (Lindzen and Nigam, 1987, hereafter LN87), resulting in WS modifications through the momentum balance (Wai and Stage, 1989; Small et al, 2005). Finally, warm mesoscale anomalies could also enhance the mixing in the PBL. This would increase the transfer of momentum from the upper layers to the ocean surface, resulting in wind speed and stress strengthening in the lower layers ("downward mixing mechanism"; Hayes et al, 1989; Wallace et al, 1989). These mechanisms have also been shown to act together to explain the proportional relation between SST and WS intensity anomalies (O'Neill et al, 2010; Koseki and Watanabe, 2010). Byrne et al (2015) also pointed out a lack of explanation for the seasonal variability in the atmospheric response to the mesoscale SST.

Impacts of these mesoscale SST-WS interactions on the atmosphere and ocean dynamics at larger scale remain relatively unknown. In an idealized framework, Hogg et al (2009) showed that it can affect the largescale ocean circulation and the gyres structure. Piazza et al (2015) recently showed that the mesoscale SST forcing in the Gulf Stream region have an upscaling impact on the tropospheric wind and storm tracks from the North American East Coast to the Mediterranean Sea. In Eastern Boundary Upwelling Systems (EBUS), WS can be significantly altered by the SST in offshore regions (Chelton et al, 2007) and also in coastal areas with strong thermal gradients due to the upwelling. In the California EBUS, Boe et al (2011) and Renault et al (2015) have shown that the nearshore wind shape is mainly driven by orographic effects, but the coupling with the SST, albeit weaker, can also modulate the nearshore WS structure. This WS modulation could affect in return the upwelling structure (Perlin et al, 2007; Jin et al, 2009), the associated coastal current system and also the eddy dynamics generated by its instability (e.g. Capet et al, 2008; Colas et al, 2012). The SST-WS 
feedback could also affect the ocean mesoscale eddies characteristics, for example through Ekman pumping (e.g. Spall, 2007a; Gaube et al, 2015) created by WS mesoscale anomalies. In the EBUS mesoscale eddies play an important role as they can account for a substantial heat transport (Colas et al, 2012) and they also largely influence the intense biological activity (Lathuilière et al, 2010; Gruber et al, 2011; Bertrand et al, 2014).

The Peru-Chile Current System (PCS) is one of the main EBUS. Its regional dynamics has often been studied using regional ocean models forced by prescribed atmospheric fluxes (e.g. Penven et al, 2005; Oerder et al, 2015) neglecting the ocean feedback on the atmosphere. Recent advances in regional modeling now allow to tackle ocean/atmosphere mesoscale coupling in a realistic framework with the objective to understand its impact on the regional dynamics. The present study analyzes the characteristics of the SST feedback on the WS in the PCS. It also aims at understanding the mechanisms of the WS intensity response to SST in order to explain its seasonal variations. Putrasahan et al (2013) used an ocean/atmosphere coupled model to study the PCS dynamics. They concluded to a weak mesoscale air-sea coupling. However our study shows contrasting results.

In the present work, we use satellite observations and a high-resolution coupled model. Details about the model and observations are provided in section 2 , along with a description of the methodology and the diagnostics. Section 3 evaluates the model realism by comparing observed and simulated fields, including the SST-WS coupling characteristics and their spatial and seasonal variations. The WS intensity dynamical response to the SST mesoscale field is analyzed in section 4. We evidenced two concurrent effects affecting the WS : one related to the Turbulent Kinetic Energy (TKE) modifications, and anotherone due to wind shear anomalies. The origin of these wind anomalies is studied through a momentum balance analysis. Results are discussed in section 5 before concluding in section 6 .

\section{Methodology}

\subsection{Observational dataset}

Satellite observations are used to characterize the SST-WS coupling and to evaluate the realism of the model solution. WS data are from the QSCAT scatterometer (Dunbar et al, 2006). We use the daily product gridded 
at $50 \mathrm{~km}$ for the period 2000-2009 processed by the Centre ERS d'Archivage et de Traitement (CERSAT, 2002). The Microwave Optimally Interpolated (MW OI) SST is a merged product from different satellite data, processed by Remote Sensing System and available at www.remss.com. It provides daily data at $0.25^{\circ}$ resolution. We use data for the 2000-2009 period. To evaluate the model solution heat fluxes and cloud cover, we use the short-wave ocean surface radiation from the International Satellite Cloud Climatology Project (ISCCP, Schiffer and Rossow, 1983; Zhang et al, 2004) for the year 2007. Its spatial resolution is $2.5^{\circ}$. Data are available through the OAFlux project (http://oaflux.whoi.edu). Rawinsonde data from the VOCALS-REx campaign (VAMOS Ocean-Cloud-Atmosphere-Land Study Regional Experiment; Wood et al, 2011) provide wind velocity and air temperature observations in the PBL along a $20^{\circ} \mathrm{S}$ zonal section for the time period between October 28th, 2008 and November 3rd, 2008.

\subsection{Regional Ocean-Atmosphere Coupled Model}

\subsubsection{Atmospheric model}

The atmospheric component is the Weather Research and Forecasting (WRF) model using the ARW (Advanced Research WRF) solver (Skamarock and Klemp, 2008) in its 3.6 version. WRF is a regional model solving the fully compressible non-hydrostatic Euler equations on a C-grid with terrain-following mass vertical coordinate. The atmospheric grid has 60 vertical sigma levels with the top of the atmosphere located at $50 \mathrm{hPa}$. We increase the WRF default vertical resolution defining 21 levels in the first $\sim 1000 \mathrm{~m}$. The horizontal resolution is $1 / 12^{\circ}$. Time step is $20 \mathrm{~s}$. A third order Runge-Kutta time-integration scheme and a 5th-order upwind-biased advection scheme in space are used.

WRF allows for the testing of a large range of parameterizations. Our configuration uses Goddard shortwave flux scheme (Chou and Suarez, 1994), the longwave Rapid Radiative Transfer Model (RRTM; Mlawer et al, 1997) and the "WSM6" microphysics scheme (Hong and Lim, 2006). Cumulus are parameterized by the BettsMiller-Janjic scheme (Janjic, 1994). We use the unified NOAH land surface model with the surface layer scheme from the fifth-generation Mesoscale Model (MM5, Chen and Dudhia, 2001). To represent the PBL physics, the 
Mellor-Yamada-Nakanishi-Niino (MYNN) 2.5 level (Nakanishi and Niino, 2009) scheme is selected, associated with its corresponding MYNN surface scheme. In our region, this PBL parameterization produces the most realistic simulation (see Sec. 3). As Perlin et al (2014) showed that the SST-WS coupling intensity is sensitive to the WRF PBL scheme, we also perform a simulation using the Yonsei University (YSU, Hong et al, 2006) PBL scheme and the MM5 surface layer parameterization (Paulson, 1970). We choose YSU for two reasons. First, we tested several PBL schemes and YSU gives the second most realistic simulation (after MYNN), both for regional climate mean state and coupling characteristics (see Sec. 4.3). Second, MYNN and YSU derive from two different momentum turbulent mixing theories. In MYNN, momentum mixing is parameterized by a Reynolds turbulent stress $\vec{\tau}$ at the layers interface, proportional to $\partial_{z} \vec{v}$, the vertical shear of horizontal velocity (all wind speed and velocities presented in this article referred to the horizontal wind) :

$$
\vec{\tau}=\rho K_{M} \partial_{z} \vec{v}
$$

with $\rho$ the air density, $K_{M}$, the momentum vertical diffusion coefficient. In YSU, other terms are included to represent the contribution of large-scale eddies to the total flux (Hong and Pan, 1996) and the entrainment flux (Hong et al, 2006). In MYNN, $K_{M}$ is locally computed on each grid point using a TKE budget (that includes air/sea turbulent fluxes). This differs from YSU where the vertical profile of $K_{M}$ is determined at each horizontal grid point using the PBL height and the air/sea turbulent fluxes. A more detailed comparison between these two momentum turbulent mixing parameterizations can be found in Perlin et al (2014).

Initial and open boundary conditions are extracted from ERA-interim reanalysis (Dee et al, 2011) 6 hours averages with an horizontal resolution of $\sim 3 / 4^{\circ}$. We consider a 1-day spinup period for the coupled simulations as the focus here is on PBL structures adjusting quickly to the oceanic mesoscale.

\subsubsection{Oceanic model}

The ocean component is the Nucleus for European Modeling of the Ocean (NEMO, Madec, 2008) model in its version 3.4. NEMO is a primitive equations ocean model that has been run in several regional configurations (e.g. Resplandy et al, 2011; Jouanno and Sheinbaum, 2013; Benshila et al, 2014). The ocean vertical grid has 
75 z-levels, with 25 levels above $100 \mathrm{~m}$. The vertical resolution ranges from $1 \mathrm{~m}$ at the surface to $200 \mathrm{~m}$ at the bottom where a partial step representation of the topography (Adcroft et al, 1997) is used. The time step is 400 s.

Horizontal tracer and momentum advection is treated with an upstream-biased (UBS) third order scheme (Farrow and Stevens, 1995; Webb et al, 1998). The vertical tracer flux is evaluated using a total variance dissipation scheme (Lévy et al, 2001) and the momentum vertical advection is a simple 2nd order centered scheme. As the UBS scheme already includes an intrinsic diffusion, we are not using any explicit horizontal diffusion/viscosity in these simulations. The vertical mixing is parameterized using an improved version of Turbulent Kinetic Energy, closure scheme (Blanke and Delecluse, 1993; Madec, 2008).

Lateral boundary conditions are 5-day averages for temperature, salinity and velocity coming from simulations performed in the Drakkar project (global oceanic simulation ORCA025-B83 performed with NEMO at $0.25^{\circ}$ horizontal resolution and 46 vertical levels; Dussin et al, 2009). A non-coupled spin-up was performed using an oceanic $1 / 12^{\circ}$ regional simulation forced by ERAinterim over the 1990-2006 period. Oceanic states of December 31, 2004 (for the simulation starting in 2005) and 2006 (for simulations starting in 2007) are used as initial conditions.

\subsubsection{Ocean-atmosphere coupling and simulations}

WRF and NEMO are coupled through the Ocean Atmosphere Sea Ice Sol (OASIS3-MCT, Valcke et al, 2013) coupler, as done by Samson et al (2014). Coupling frequency is $1 \mathrm{~h}^{-1}$. The same horizontal resolution $\left(1 / 12^{\circ}\right)$ and the same horizontal grid $\left(\left[10^{\circ} \mathrm{N}-30^{\circ} \mathrm{S}\right]\right.$ and $\left.\left[100{ }^{\circ} \mathrm{W}-60^{\circ} \mathrm{W}\right]\right)$ are used for NEMO and WRF. There is no restoring of any kind in the atmosphere or in the ocean. Fig. 1 presents a scheme of the vertical levels distribution in the coupled model. Ocean velocity in the surface layer is named $\overrightarrow{v_{1}^{o}}$. In the atmosphere, $z_{N}$ is the height of level $\mathrm{N}$, where wind velocities $\overrightarrow{v_{N}}$ and the air density $\rho\left(z_{N}\right)$ are defined. The height of the first atmospheric level is $z_{1}=10 \mathrm{~m}$. The turbulent stress $\overrightarrow{\tau_{N}}$ is defined at the top of layer $\mathrm{N}$.

The air/sea stress conditions (i.e. WS) are computed in surface layer parameterization of WRF. Both MYNN and MM5 schemes are based on the Monin-Obukov similarity theory (Monin and Obukhov, 1954). WS is 
expressed by :

$$
\begin{gathered}
\overrightarrow{\tau_{s}}=\rho\left(z_{1}\right) u^{* 2} \frac{\overrightarrow{v_{1}}}{\left\|\overrightarrow{v_{1}}\right\|} \\
u^{*}=\frac{k_{0}\left\|\overrightarrow{v_{1}}\right\|}{\ln \left(\frac{z_{1}}{z_{0}}\right)-\psi\left(\frac{z_{1}}{L}\right)}
\end{gathered}
$$

with $k_{0}$ the Von Karman constant, $z_{0}$ the roughness length. $\psi$, the stability function, depends on the chosen scheme and L, the Monin-Obukov length. However, at the air-sea interface, the WS actually depends on the surface wind velocity relative to the surface ocean current (Dawe and Thompson, 2006; Song et al, 2006). This impacts the WS mesoscale structure (Chelton et al, 2004). In order to take this effect into account, the stress conditions at air-sea interface are modified : equations (3) and (4) are computed using $\overrightarrow{v_{1}}-\overrightarrow{v_{1}^{o}}$ instead of $\overrightarrow{v_{1}}$ (Lemarié, 2015). This requires modifications in several WRF routines that are now available in the latest model releases (from version 3.6).

Two simulations using different PBL schemes are performed: a 4-year simulation (for the period 2005-2008) using the MYNN PBL scheme named CPLM and a 1-year simulation (for the year 2007) with the YSU PBL scheme named CPLY (see Sec. 3.3.1).

\section{$2.3 \mathrm{SST}$ and WS fields processing}

\subsubsection{Fields regridding}

Observed and simulated WS and SST fields have different spatial resolutions. For an accurate comparison, the fields are regridded on the same $0.5^{\circ}$ grid (for each QSCAT data point, the model field is averaged over the surrounding $0.5^{\circ}$ square box). We refer to these fields as CPLM50 and CPLY50. To study the coupling characteristics in the observations, the $0.25^{\circ} \mathrm{MW}$ OI SST is also regridded on the $0.5^{\circ}$ QSCAT grid. Finally, to directly compare the simulated and MW OI SST, we also regrid the model field on the $0.25^{\circ} \mathrm{MW}$ OI grid. We refer to these fields as CPLM25 and CPLY25 SST. 


\subsubsection{Preprocessing for SST-WS coupling analysis}

In the coastal region, orographic effects create WS mesoscale anomalies more intense than the SST-induced ones (Boe et al, 2011; Renault et al, 2015). Desbiolles et al (2014) showed that in EBUS a nearshore strip of at least $100 \mathrm{~km}$ should be removed to properly study the SST influence on WS mesoscale anomalies. Here, we discard the first $150 \mathrm{~km}$ nearshore from the coupling characteristics analysis.

To isolate the mesoscale structures, SST and WS intensity daily fields are smoothed using a Gaussian spatial filter with a standard deviation of $150 \mathrm{~km}$. Mesoscale anomalies of a field $\phi$ (SST or $\left\|\overrightarrow{\tau_{s}}\right\|$ ) are defined as $\phi^{\prime}=\phi-\bar{\phi}$, with $\bar{\phi}$ the smoothed field. In the following, we simply refer to $\phi^{\prime}$ as anomalies and large-scale field refers to the smoothed field $\bar{\phi}$. Figure 2 represents CPLM SST and WS intensity anomalies for July 2007. The filtering efficiently removes the large scale patterns and reveals correlated structures between the two fields, consistently with relation (1).

\subsubsection{SST-WS coupling characteristics}

Relation (1) between SST and WS intensity anomalies is evaluated and characterized during (late) austral summer and winter. Following Chelton et al (2007), we use 29-day averaged periods (to remove weather synoptic variability) overlapping with 7-day intervals. For summer (winter) 13 periods from January to April (JulyOctober, respectively) are selected. The WS intensity is computed using WS daily mean intensity averaged over 29-day periods

A scatterplot of WS intensity anomalies as a function of SST anomalies is generated using all points of the 13 maps. The scatterplot correlation $\mathrm{R}$ indicates the strength of the linear relationship. Correlations are significant within a $95 \%$ confidence level. They are presented in section 3.3.1 (see Table 1).

As in previous studies (e.g. Chelton et al, 2001; Desbiolles et al, 2014; Perlin et al, 2014), the SST axis is divided into $0.1{ }^{\circ} \mathrm{C}$ intervals and the WS intensity anomaly means and standard deviations are computed for each SST interval. A "binned" scatterplot is generated using these means and standard deviations. Intervals containing less than $1 \%$ of the points are discarded. An example can be found on Figure 7 in Section 3.3.1. 
We compute the binned scatterplot slope, i.e. the Regression Coefficient (RC) associated to relation (1). RC represents the intensity of the WS response to a given SST anomaly. In the following we describe the coupling characteristics $\mathrm{R}$ and $\mathrm{RC}$ in the PCS.

\subsection{Composite of vertical profiles}

To study the PBL response to the SST anomalies we compute composites of vertical profiles of air temperature and wind speed anomalies above warm $\left(S S T^{\prime}>0.1{ }^{\circ} C\right)$ and cold $\left(S S T^{\prime}<-0.1{ }^{\circ} C\right)$ SST anomalies (Sec. 4.1 .2 and 5.2). Wind speed increases with height, reaching its maximum $Z_{\max }$ at a few $100-\mathrm{m}$ height. $Z_{\max }$ varies spatially over the domain. To obtain composite profiles, the vertical axis is rescaled for each profile so that $Z_{\max }=Z_{\max }^{\operatorname{mean}}$, with $Z_{\max }^{\text {mean }}$ the height of the maximum of the wind speed mean profile (spatial mean over the domain). The same methodology is applied to air temperature using the inversion height (Sec. 5.2).

\section{Model realism and mesoscale coupling description}

\subsection{Mean state}

The realism of our reference simulation (CPLM) is first evaluated by comparing annual means of the WS and SST fields (Fig. 3). A realistic mean state is important to study the mesoscale coupling as it affects the intensity of the WS response to SST anomalies (see O'Neill et al, 2012, and Sec. 3.3.2 and 4.2). Figure 3 shows that the regional patterns are reproduced by the model. South of the equator, the wind blows north-westward with a stronger intensity near the Chile coast at $30{ }^{\circ} \mathrm{S}$ and between $6{ }^{\circ} \mathrm{S}$ and $24{ }^{\circ} \mathrm{S}$ offshore. Near the coast, the wind is alongshore and its intensity decreases shoreward. This decrease appears to be slightly overestimated by the model in some regions (e.g. the $\left[7^{\circ} \mathrm{S}-13^{\circ} \mathrm{S}\right]$ coastal segment) when compared to QSCAT data. The SST field presents a cold tongue along the Peru-Chile coast, characteristic of a wind-driven coastal upwelling. Simulated SST are colder $\left(\sim 1^{\circ} \mathrm{C}\right)$ than the satellite observations close to the coast. Note that the $25 \mathrm{~km}$ MW IO SST misses part of the upwelling structure in the very nearshore. So, within a coastal strip, the SST has been extrapolated from offshore and the actual SST is expected to be colder in the central Peru coastal region. 
South of the equator, spatial correlations between observed and simulated fields are 0.97 for WS intensity and 0.95 for SST. Along the equator, CPLM underestimates the cold tongue extension and presents a $2{ }^{\circ} \mathrm{C}$ warm bias, associated to an overestimated WS intensity $\left(0.008 \mathrm{~N} \mathrm{~m}^{-2}\right.$ bias). In the northern part of the domain the model solution is less realistic: WS intensity is $\sim 0.02 \mathrm{~N} \mathrm{~m}^{-2}$ too weak and the SST is up to $2{ }^{\circ} \mathrm{C}$ too warm. This is because the atmospheric model parameterizations, chosen to realistically reproduce the PCS climate, are certainly less adequate for the trade winds convergence zone and intense deep convection areas.

Common biases when modeling the lower atmosphere in EBUS are an unrealistic downward short-wave flux above the ocean (Ma et al, 1996; Davey et al, 2002; Meehl et al, 2005) and an underestimation of the low cloud cover (e.g. Wyant et al, 2010; De Szoeke et al, 2012). In coupled models, this can lead to a large SST bias (De Szoeke et al, 2010). CPLM flux is compared to ISCCP data in Fig. 4. It shows a large pattern of low short-wave $\left(\sim 175 \mathrm{~W} \mathrm{~m}^{-2}\right)$ off the Peru-Chile coast from $12{ }^{\circ} \mathrm{S}$ to $30{ }^{\circ} \mathrm{S}$ that can be due to the presence of low clouds. West of $90^{\circ} \mathrm{W}$, the short-wave flux is higher. North of the equator, the observed low short-wave strip along $6{ }^{\circ} \mathrm{N}$ and the minimum in the Panama Bight region are poorly simulated. This may explain the warm SST bias in this area (Fig. 3).

The large-scale wind vertical structure has a big impact on the atmospheric response to SST mesoscale patterns (see Sec. 4.1). Zonal sections at $20^{\circ} \mathrm{S}$ of the wind velocities are shown on Fig. 5. The simulated wind presents similar structures than the VOCALS-REx observations. Near the surface, the meridional wind flows northward with a maximum jet at $\sim 900 \mathrm{hPa}$ and its intensity decreases nearshore (Fig. 5a and b). This decrease is somewhat underestimated by the model, contrarily to what is seen on Fig. 3. This difference may be attributed to the fact that the comparisons in Figs. 3 and 5 use different datasets (QSCAT and in situ rawinsonde data) over different periods (annual mean and several days average). At height, a southward meridional velocity is associated to the poleward branch of the Hadley cell. The height of the wind reversal is $\sim 500 \mathrm{hPa}$ at $85^{\circ} \mathrm{W}$ both in model and observations and it decreases toward the shore $\left(\right.$ at $\left.72^{\circ} \mathrm{W}\right)$ reaching $\sim 980 \mathrm{hPa}$ in observations and $\sim 940 \mathrm{hPa}$ in the model. Near the surface, the zonal wind (Fig. 5c and d) flows westward and decreases nearshore. At height, it flows eastward and the reversal height decreases from $700 \mathrm{hPa}$ at $85^{\circ} \mathrm{W}$ to $\sim 950 \mathrm{hPa}$ at $72{ }^{\circ} \mathrm{W}$. These patterns are captured in the model solution. 
3.2 Mesoscale activity

Statistics of the mesoscale fields are examined for simulated and observed WS intensity and SST. Anomalies, as defined in Sec. 2.3.2, are computed for each monthly field of CPLM25 SST, CPLM50 WS intensity and observations for the year 2007 .

Both the probability density function (PDF) and the monthly-mean absolute values show that SST anomalies have more extreme values in the model solution than in observations (Fig. 6a, b). CPLM25 captures well the seasonal cycle of the mean SST anomaly with enhanced (reduced) anomalies in autumn (summer, respectively). Similar results are obtained for WS intensity anomalies (Fig. 6c, d): CPLM50 wind anomalies are more intense than in observations but have the same seasonal variability. Note that having stronger WS intensity and SST anomalies is consistent with relation (1), assuming realistic coupling characteristics (Sec. 3.3). Interestingly, WS intensity and SST anomalies seasonal cycles are not in phase (maximum in winter for WS intensity and in fall for SST). This indicates that coupling characteristics R and RC vary in time (Sec. 3.3).

\subsection{SST-WS mesoscale coupling}

\subsubsection{Comparison between model and observations}

WS intensity and SST fields from CPLM, CPLM50 and observations are processed as described in Sec. 2.3 to examine the mesoscale coupling characteristics. Binned scatterplots for austral winter in the Peru region (from $9{ }^{\circ} \mathrm{S}$ to $18{ }^{\circ} \mathrm{S}$ and from $95^{\circ} \mathrm{W}$ to $150 \mathrm{~km}$ offshore; red box in Fig. 2) are shown on Fig. 7. All panels exhibit a clear linear relationship between SST and WS intensity anomalies. R and RC between WS intensity and SST are larger $(\sim 50 \%$ for $\mathrm{RC})$ in the model $(\mathrm{R}=0.77)$ than in the observations $(R=0.59)$. The model overestimates both the intensity of the SST anomalies (Sec. 3.2) and RC. This may be why the part of the total WS intensity variance explained by relation (1), i.e. $R^{2}$, is larger in the model than in the observations. Note that the regriding does not affect much the WS intensity dependence to the SST, as R and RC are not very different for CPLM and CPLM50. 
The same diagnostics are computed for the summer season and for the southern part of our domain ("Chile" region, from $18^{\circ} \mathrm{S}$ to $27^{\circ} \mathrm{S}$ and from $150 \mathrm{~km}$ offshore to $95^{\circ} \mathrm{W}$; Fig. 2). Results are presented in Table 1. CPLM and CPLM50 values are always close. Again, $\mathrm{R}$ is smaller in observations than in the model, except off Chile in summer. $\mathrm{RC}$ values are higher in the model than in the observations in winter $(\sim 50 \%$ and $25 \%$ larger for Peru and Chile, respectively) while they are very close in summer ${ }^{1}$. The simulation and the observations share similar spatial and temporal variability. First, the coupling characteristics are weaker in summer than in winter. This seasonal cycle is also observed for the entire QSCAT period (2000-2009) and in the 4 years (2005-2008) of CPLM (not shown). Second, R and RC are larger off Peru than off Chile.

As evidenced by Chelton et al (2001), spatial derivatives of (1) lead to :

$$
\operatorname{div}\left(\overrightarrow{\tau_{s}^{\prime}}\right) \propto \operatorname{grad}_{d w}\left(S S T^{\prime}\right)
$$

$$
\operatorname{curl}\left({\overrightarrow{\tau_{s}}}^{\prime}\right) \propto \operatorname{grad}_{c w}\left(S S T^{\prime}\right)
$$

with $\operatorname{curl}\left(\overrightarrow{\tau_{s}}\right)=\vec{\nabla} \wedge \overrightarrow{\tau_{s}} \cdot \vec{k}$, the vertical component of the stress curl, $\vec{k}$ being the vertical unit vector. $\operatorname{grad}_{d w}\left(S S T^{\prime}\right)$ and $\operatorname{grad}_{c w}\left(S S T^{\prime}\right)$ are the downwind and crosswind projections of the gradient, respectively : $\operatorname{grad}_{d w}\left(S S T^{\prime}\right)=\left\|\overrightarrow{\operatorname{grad}}\left(S S T^{\prime}\right)\right\| \cos (\theta)$ and $\operatorname{grad}_{c w}\left(S S T^{\prime}\right)=\left\|\overrightarrow{\operatorname{grad}}\left(S S T^{\prime}\right)\right\| \sin (\theta), \theta$ being the counterclockwise angle from $\overrightarrow{\operatorname{grad}}\left(S S T^{\prime}\right)$ to $\overrightarrow{\tau_{s}}$. We have examined these relations and results are summarized in Tables 2 and 3. As for relation (1), $\mathrm{R}$ values are overestimated in the model. Observed and simulated $\mathrm{RC}$ are very close in summer while in winter the simulated $\mathrm{RC}$ is $\sim 30 \%$ too large. The spatial and seasonal variability are similar in the model and in observations: R and RC are stronger in winter than in summer and slightly higher off Peru than off Chile, except for relation (6) in summer.

In contrast with our results, Putrasahan et al (2013) obtained stronger coupling characteristics in summer than in winter. However, they used a different methodology in the computation of the binned scatterplot. They included bins with extreme SST gradients that contains very few points. This might give an important weight to extreme SST values and might influence RC values. Moreover, they computed the correlations from the binned

\footnotetext{
1 Perlin et al (2014) tested several PBL schemes using the 3.3 version of WRF. They obtained a large overestimation of RC with MYNN, inconsistent with our results. Improvements in this parameterization between version 3.3 and 3.6 reduces RC (not shown).
} 
scatterplots while we did it directly on the SST and WS intensity fields before binning (correlations of our binned scatterplot are always higher than 0.98).

\subsubsection{Spatial variations of the coupling characteristics}

To further investigate the spatial variations of the coupling characteristics, we take advantage of the high resolution of CPLM to map R and RC for relation (1). Every 12 points of the horizontal grid, we estimate the coupling diagnostics using all points included in a $450 \mathrm{~km}$-large square (moving) box centered on this grid point.

Only RC values for winter are shown in Fig. 8 (the R map presents similar patterns). The RC map presents a large area off Peru with values $\sim 1.510^{-2} \mathrm{~N} \mathrm{~m}^{-2}{ }^{\circ} \mathrm{C}^{-1}$. Off Chile, $\mathrm{RC}$ values are $\sim 1.310^{-2} \mathrm{~N} \mathrm{~m}^{-2}{ }^{\circ} \mathrm{C}^{-1}$ nearshore while they are much smaller $\left(<0.810^{-2} \mathrm{~N} \mathrm{~m}^{-2}{ }^{\circ} \mathrm{C}^{-1}\right)$ offshore. Near the coast, the northern and southern regions are separated by a minimum $\left(\sim 0.410^{-2} \mathrm{~N} \mathrm{~m}^{-2}{ }^{\circ} \mathrm{C}^{-1}\right)$ around $20^{\circ} \mathrm{S}$.

Several factors are possibly affecting the coupling characteristics. Chelton et al (2007) and Castelao (2012) showed evidence that the air-sea mesoscale coupling is more efficient under steady wind conditions. The surface wind steadiness $(\mathrm{St})$ is defined as

$$
S t=\frac{\left\|\left\langle\overrightarrow{v_{1}}\right\rangle\right\|}{\left\langle\left\|\overrightarrow{v_{1}}\right\|\right\rangle}
$$

with \langle\rangle the temporal averaging. St is close to 1 when the wind is steady, and decreases when the wind often changes direction. Winter St is represented on Figure 8. Off Chile, low RC values correspond to the region with lower $(<0.9)$ steadiness. However, the steadiness spatial distribution does not explain the low RC north of $9^{\circ} \mathrm{S}$ and nearshore around $20^{\circ} \mathrm{S}$. O'Neill et al (2012) showed that RC also depends on the large-scale wind intensity. The large RC values off Peru corresponds to the strongest wind area $\left(>8 \mathrm{~m} \mathrm{~s}^{-1}\right)$ while the nearshore Chile region south of $20^{\circ} \mathrm{S}$ has a $7.5 \mathrm{~m} \mathrm{~s}^{-1}$ wind intensity and intermediate RC values. Finally, the nearshore region near $20^{\circ} \mathrm{S}$ and the smallest $\mathrm{RC}$ region off Chile correspond to the weakest wind $\left(<7 \mathrm{~m} \mathrm{~s}^{-1}\right)$. 


\subsubsection{Decomposition of the WS anomalies}

Larger (smaller) $K_{M}$ over warm (cold, respectively) waters tends to increase (decrease) the turbulent stress $\vec{\tau}$ according to equation (2). Conversely, a weaker (stronger) wind shear tends to decrease (increase) it. Thus,

\footnotetext{
2 The WS $\overrightarrow{\tau_{s}}$ being the turbulent stress $\vec{\tau}$ condition at the air-sea interface, the intensity of both fields are highly correlated $(>0.99)$ and are related by $\tau_{s}^{\prime}=\alpha \tau_{1}^{\prime}$ with $\alpha=0.95$.
} 
these two effects can compensate each other. To investigate this, $\vec{\tau}$ is decomposed as follows :

$$
\vec{\tau}=\rho K_{M} \partial_{z} \vec{v}=\underbrace{\rho K_{M} \overrightarrow{\partial_{z} \vec{v}}}_{\overrightarrow{\tau_{a}}}+\underbrace{\rho K_{M} \partial_{z} \vec{v}}_{\overrightarrow{\tau_{b}}}
$$

- denotes the large-scale field (a Gaussian filter is applied as described in section 2.3.2) and.$^{\prime}$ denotes the mesoscale anomalies. A similar decomposition for the turbulent stress shear was introduced by Koseki and Watanabe (2010). Our decomposition separates the stress proportional to the wind shear anomalies $\overrightarrow{\tau_{b}}$ from $\overrightarrow{\tau_{a}}$ (which does not depend on $\partial_{z} \overrightarrow{v^{\prime}}$ ). In the following, we focus on the stress anomalies, so equation (8) was filtered (see section 2.3.2) to isolate mesoscale fields : $\overrightarrow{\tau^{\prime}}=\overrightarrow{\tau_{a}^{\prime}}+\overrightarrow{\tau_{b}^{\prime}}$. Note that : $\overrightarrow{\tau_{a}^{\prime}}=\left(\rho K_{M} \overline{\partial_{z} \vec{v}}\right)^{\prime}=\left(\rho \overline{K_{M}} \overline{\partial_{z} \vec{v}}+\right.$ $\left.\rho K_{M}^{\prime} \overline{\partial_{z} \vec{v}}\right)^{\prime}=\rho K_{M}^{\prime} \overline{\partial_{z} \vec{v}}$. The mesoscale anomalies $\overrightarrow{\tau_{a}^{\prime}}$ are entirely created by the mixing coefficient anomalies.

In the MYNN formulation, the mixing coefficient is parameterized using a TKE formulation. The positive (negative) anomalies of $K_{M}$ above warm (cold) SST anomalies shown in Fig. 9a are due to positive (negative) TKE anomalies (not shown). A TKE budget examination indicates that TKE anomalies are caused at the first order by the temperature turbulent flux (the buoyancy production term) anomalies with a negligible contribution of the wind shear term (not shown). This confirms that equation (8) adequately separates the turbulent stress independant from the wind shear $\left(\overrightarrow{\tau_{a}}\right)$ from the stress proportional to the wind shear anomalies $\left(\overrightarrow{\tau_{b}}\right)$. SST anomalies create air temperature anomalies and drive TKE anomalies $\left(K_{M}^{\prime}\right)$ through atmospheric stability modifications. It leads to turbulent stress anomalies $\overrightarrow{\tau_{a}^{\prime}}$. This modifies the momentum balance (Sec. 4.1.2) and generates wind shear anomalies that in return affect the turbulent stress $\overrightarrow{\tau_{b}^{\prime}}$ (but not TKE or $K_{M}$ ).

As the turbulent stress anomalies are mainly downwind (not shown), (8) gives $\tau_{1}^{\prime} \approx \tau_{a}^{\prime}+\tau_{b}^{\prime}$, with $\tau_{1}^{\prime}, \tau_{a}^{\prime}$ and $\tau_{b}^{\prime}$ the norms of $\vec{\tau}_{1}^{\prime}, \vec{\tau}_{1}^{\prime}$ and $\vec{\tau}_{2}^{\prime}$, respectively. Note that this also means that $\left\|\partial_{z} \overrightarrow{v^{\prime}}\right\| \approx\left(\partial_{z} \overrightarrow{v^{\prime}}\right) \cdot \frac{\vec{v}}{V} \approx \partial_{z} V$. Figure 10 presents the three terms (at $20 \mathrm{~m}$ height). $\tau_{1}^{\prime}$ and SST anomalies are highly correlated $(\mathrm{R}=0.71)$, with a RC of $0.710^{-2} \mathrm{~N} \mathrm{~m}^{-2}{ }^{\circ} \mathrm{C}^{-1}$. The SST anomalies create $K_{M}$ anomalies that induce a positively correlated $\tau_{a}^{\prime}$ pattern (with $\mathrm{RC} \approx 2.010^{-2} \mathrm{~N} \mathrm{~m}^{-2}{ }^{\circ} \mathrm{C}^{-1}$ ). Wind shear anomalies generated by such mixing induce instead a $\tau_{b}^{\prime}$ pattern with opposite sign that partly compensates $\tau_{a}^{\prime}\left(\right.$ with $\mathrm{RC} \approx-1.310^{-2} \mathrm{~N} \mathrm{~m}^{-2}{ }^{\circ} \mathrm{C}^{-1}$ ). 


\subsubsection{What drives wind speed vertical shear anomalies?}

We now investigate the mechanisms generating near-surface wind shear anomalies. In particular, we examine whether the wind speed is modified because of pressure or turbulent stress perturbations. To this aim, we first investigate why the near-surface wind speed is faster (slower) above warm (cold, respectively) water and why wind anomalies change with height (see Fig. 9c).

The wind velocity variations are driven by the momentum balance :

$$
\partial_{t} \vec{v}+(\vec{v} \cdot \vec{\nabla}) \vec{v}=\partial_{z}\left(\frac{\vec{\tau}}{\rho}\right)-f \vec{k} \wedge \vec{v}-\frac{1}{\rho} \overrightarrow{\operatorname{grad}} P
$$

with $f$ the Coriolis parameter and $P$ the pressure. The term $\partial_{t} \vec{v}+\vec{v} \cdot \vec{\nabla} \vec{v}$ represents the Lagrangian acceleration of an air parcel. $\partial_{z}\left(\frac{\vec{\tau}}{\rho}\right)$ represents the tendency due to the turbulent vertical mixing of momentum. $-f \vec{k} \wedge \vec{v}$ is the Coriolis force and $-\frac{1}{\rho} \overrightarrow{\operatorname{grad}} P$ the pressure gradient. Following O'Neill et al (2010), (9) can be written using natural coordinates. Here we only focus on the downwind momentum budget:

$$
V \operatorname{grad}_{d w}(V)=\frac{\vec{v}}{V} \cdot \partial_{z}\left(\frac{\vec{\tau}}{\rho}\right)-\frac{1}{\rho} \operatorname{grad}_{d w}(P)
$$

with $V=\|\vec{v}\|$ and considering that $\frac{\vec{v}}{V} \cdot\left(\partial_{t} \vec{v}\right) \ll V \operatorname{grad}_{d w}(V)$. (10) describes the driving of the Lagrangian acceleration following a streamline $\partial_{t} V+V \operatorname{grad}_{d w}(V)$, that can be approximated by $V \operatorname{grad}_{d w}(V)$ as $\partial_{t} V \ll$ $V \operatorname{grad}_{d w}(V)$ (not shown).

Time averaging of equation (10) terms for July 2007 (see Appendix) are computed and spatially filtered to analyze mesoscale anomalies. Near the surface, downwind wind speed gradient are colocated with downwind SST gradients (not shown) : air parcels are decelerated (accelerated) when flowing from warm to cold (cold to warm, respectively) waters, which is consistent with the surface wind anomalies shown in Fig. 9c. Hence, the acceleration vertical shear $\partial_{z}\left(V \operatorname{grad}_{d w}(V)\right)$ above the frontal regions is responsible for the wind speed shear anomalies above SST anomalies. In the following we analyze the mechanisms responsible for wind speed 
mesoscale anomalies using (10) and its vertically derived expression :

$$
\partial_{z}\left(V \operatorname{grad}_{d w}(V)\right)=\partial_{z}\left(\frac{\vec{v}}{V} \cdot \partial_{z}\left(\frac{\vec{\tau}}{\rho}\right)\right)-\partial_{z}\left(\frac{1}{\rho} \operatorname{grad}_{d w}(P)\right)
$$

We compute composites of the different terms above the regions of positive $\left(\operatorname{grad}_{d w} S S T^{\prime}>210^{-5}{ }^{\circ} \mathrm{C}\right.$ $\mathrm{m}^{-1}$ for cold to warm transition) and negative $\left(\operatorname{grad}_{d w} S S T^{\prime}<-210^{-5}{ }^{\circ} \mathrm{C} \mathrm{m}^{-1}\right.$ for warm to cold transition) downwind SST gradient anomalies. Vertical profiles of the anomalies of the terms in (10) are represented on Fig. 11. Momentum is redistributed in the PBL as the air parcels flowing from warm to cold waters are decelerated below $100 \mathrm{~m}$ and accelerated above (Fig. 11a). The deceleration is strongest near the surface (Fig. 11a), creating a strong near-surface wind shear. Below $100 \mathrm{~m}$, the vertical mixing term largely dominates over pressure (Fig. 11a). Thus, the deceleration and its vertical shear (Fig. 11b) in the lower layers are mainly due to the effect of turbulent stress shear perturbations, while acceleration of the wind above $100 \mathrm{~m}$ is driven by the pressure gradient. The pressure gradient role is further discussed in section 5.2.

The cold to warm composites (Fig. 11c) present a symmetrical situation : lower layers (below $200 \mathrm{~m}$ ) are accelerated while upper layers are decelerated. Near the surface, the pressure gradient is stronger than in the warm to cold case. However, the turbulent stress shear remains the main forcing of the acceleration, while above $50 \mathrm{~m}$, the pressure effect becomes important (Fig. 11c).

In conclusion, in both cases, below $\sim 100 \mathrm{~m}$, the wind shear anomalies are driven by the turbulent stress perturbations, while the effect of the pressure gradient is an order of magnitude weaker. Previous studies have also examined the momentum budget over SST fronts. Consistency between our results and theirs are further discussed in Sec. 5.2.

4.2 Seasonal variations of the SST feedback on WS

\subsubsection{Origin of the seasonal variations}

We now use the stress decomposition (Sec. 4.1.1) to explain the seasonal variation of the coupling strength (Table 1). Table 4 presents the RC between SST anomalies and $\tau_{1}^{\prime}, \tau_{a}^{\prime}$ and $\tau_{b}^{\prime}$ during winter (July) and summer 
(January). Both $\tau_{a}^{\prime}$ and $\tau_{b}^{\prime}$ responses are increased by $\sim 60 \%$ from summer to winter and so is the total coupling strength (RC between SST' and $\tau_{1}^{\prime}$ ). Figure 12 helps to understand whether $\tau_{a}^{\prime}$ and $\tau_{b}^{\prime}$ seasonal variation can be attributed to mixing coefficient and/or wind shear variations.

The binned scatterplot of $K_{M}^{\prime}$ with respect to SST' (Fig. 12a) shows that RC changes little between winter and summer (1.24 and $1.4510^{-2} \mathrm{~m}^{-2} \mathrm{~s}^{-1}{ }^{\circ} \mathrm{C}^{-1}$, respectively, i.e. a $14 \%$ increase). Thus, the stronger $\tau_{a}^{\prime}$ response in winter is related to the large-scale wind shear seasonal variation (the intensity of $\overline{\partial_{z} \vec{v}}$ at $20 \mathrm{~m}$ is $\sim$ $1.110^{-2} \mathrm{~s}^{-1}$ in winter and $\sim 0.710^{-2}$ in summer, i.e. a $60 \%$ decrease).

The binned scatterplot of $\left\|\partial_{z} \vec{v}^{\prime}\right\|$ (Fig. 12b) shows that SST anomalies create wind velocity shear anomalies $\sim 60 \%$ stronger in winter than in summer while the mixing coefficient spatial average changes little $(5.9$ and 5.7 $10^{-2} \mathrm{~m}^{-2} \mathrm{~s}^{-1}$ in winter and summer, respectively). Thus, the larger $\tau_{b}^{\prime}$ response in winter is mainly driven by enhanced wind velocity shear anomalies.

Both $\tau_{a}^{\prime}$ and $\tau_{2}^{\prime}$ seasonal changes are attributed to changes in the intensity of the wind velocity shear (largescale and anomalies, respectively) with similar relative amplitudes. Note that the stronger large-scale wind velocity shear leads to stronger wind velocity shear anomalies, as given by the momentum balance through stronger stress shear anomalies and wind acceleration (not shown). Overall, this implies that the large-scale wind shear seasonal variation is responsible for the seasonal variation of the WS response to SST anomalies.

\subsubsection{Large-scale wind shear}

We here investigate the origin of the large-scale wind velocity shear seasonal variation. The WS is the boundary condition of the turbulent stress at the air/sea interface and its intensity is proportional to the square of the surface wind speed $\left(V_{s}^{2}\right)$. Thus, using (2) we obtain

$$
V_{s}^{2} \propto \tau_{s} \sim\left\|\rho K_{M} \partial_{z} \vec{v}\right\|
$$

The horizontal smoothing of (12) leads to $\overline{V_{s}^{2}} \propto\left\|\rho \overline{K_{M}^{\prime} \partial_{z} \vec{v}^{\prime}}+\rho \overline{K_{M}} \overline{\partial_{z} \vec{v}}\right\|$, with $\overline{K_{M}^{\prime} \partial_{z} \vec{v}} \ll \overline{K_{M}} \overline{\partial_{z} \vec{v}}$. As $\overline{K_{M}}$ presents weak seasonal variation (see Sec. 4.2.1) we can approximate $\overline{V_{s}^{2}} \propto\left\|\overline{\partial_{z} \vec{v}}\right\|$. 
The validity of this relation is shown on Fig. 13a. Monthly means of $\overline{V_{s}^{2}}$ and the wind velocity shear intensity $\left\|\overrightarrow{\partial_{z} \vec{v}}\right\|$ (computed at $20 \mathrm{~m}$, between the first two model levels) are strongly correlated $(\mathrm{R}=0.97)$. Thus, the enhanced large scale velocity vertical shear in winter is associated to the surface wind speed strengthening. The surface wind winter intensification is a well-known characteristic of the PCS (Fig. 13b) caused by the equatorward seasonal migration of the South Pacific anticyclone (e.g. Strub et al, 1998). These large-scale wind conditions lead to more efficient momentum vertical mixing during winter in the PCS.

\subsection{Sensitivity to the PBL parameterization}

To test the sensitivity of the results to the PBL parameterization, a second simulation (CPLY) was performed using the YSU PBL scheme (see Sec. 2.2.1). The realism of the large-scale fields is somewhat altered in CPLY compared to CPLM (not shown). In particular, an overestimated short-wave surface flux results in a warm mean bias over the Peru-Chile region $\left(>0.5^{\circ} \mathrm{C}\right.$; not shown) that was not present in CPLM. The mean WS remains quite realistic in CPLY. Table 1 presents the seasonal coupling characteristics in CPLY. As in CPLM, R and RC are slightly overestimated with respect to observed values, while regional and seasonal variations are realistic.

Figure 9 presents mixing coefficient and wind speed anomalies for CPLM and CPLY. $K_{M}$ values are weaker in CPLY than in CPLM (Fig. 9a) as also shown by Perlin et al (2014) and the large-scale wind speed shear is stronger in CPLY (Fig. 9b). Warm (cold) anomalies are associated with enhanced (reduced, respectively) mixing coefficient (Fig. 9a) and positive (negative) surface wind speed anomalies with similar intensities in both simulations (Fig. 9c). However, in the first $100 \mathrm{~m}$, the wind speed vertical shear anomalies are much weaker in CPLY. The downwind momentum balance in CPLY shows that the surface acceleration is mainly due to the turbulent mixing with a negligible contribution of the pressure gradient (not shown). It also shows a weaker turbulent mixing vertical shear in CPLY than in CPLM which explains the weaker wind speed vertical shear anomalies.

In CPLY, the turbulent stress formulation includes additional terms to equation (2) (see section 2.2.1). However the anomalies of those terms are negligible (not shown), so the same turbulent stress decomposition as in CPLM (Sec. 4.1.1) can be applied. Values are given in Table 4 for the winter season. RC for $\tau_{1}^{\prime}$ is reduced in 
CPLY. Nevertheless, the weaker wind shear anomalies in CPLY create a much weaker compensation by $\tau_{2}^{\prime}$ than in CPLM. Overall, the total stress anomalies have a comparable magnitude in the two simulations.

Furthermore, as in CPLM, the response of $K_{M}$ to SST anomalies is unchanged in CPLY between summer and winter ( $\mathrm{RC} \sim 0.33$ and $0.36 \mathrm{~m}^{2} \mathrm{~s}^{-1}{ }^{\circ} \mathrm{C}^{-1}$, respectively). The enhanced large-scale wind shear between summer and winter $\left(\left\|\overrightarrow{\partial_{z}} \vec{v}\right\|\right.$ at $20 \mathrm{~m}$ is 1.4 and $2.810^{-2} \mathrm{~s}^{-1}$, respectively) explains the seasonal variation of the coupling strength in CPLY. This confirms that the role of the large-scale wind shear in modulating the seasonal WS-SST response is rather robust and does not depend on the choice of the model parameterizations.

\section{Discussion}

\subsection{Sensitivity to the PBL parameterization}

We have examined the atmospheric response to the SST anomalies with two different PBL schemes. Both simulations are rather consistent as they reproduce the observed SST-WS coupling and its seasonal variability related to those of the background wind shear. CPLM and CPLY have SST-induced surface wind speed anomalies of similar amplitude, created by turbulent mixing anomalies above frontal regions.

The major difference between CPLY and CPLM is the wind shear response to the SST anomalies. This confirms results from Perlin et al (2014) showing that YSU creates weak wind speed shear anomalies compared to the TKE-based parameterizations. Hashizume et al (2002) observed in the EEP an enhanced (reduced) wind velocity shear above cold (warm, respectively) SST anomalies, consistent with CPLM results but not with CPLY. TKE-based parameterizations like MYNN are more accurate under stable conditions (Hu et al, 2010; Shin and Hong, 2011) like those in the PCS. Furthermore, in MYNN, $K_{M}$ is computed at each level using local variables and, thus, can represent a progressive vertical adjustment to SST anomalies, while YSU prescribes a specific (analytical) shape for $K_{M}$ vertical profile from the surface forcing (Hong and Pan, 1996) considering that the PBL instantaneously adjusts to surface anomalies. As noticed by Perlin et al (2014), this could be a limitation to represent accurate mesoscale air-sea interactions. In particular, above a SST front, the horizontal advection 
does not allow the entire vertical column to adjust to the underlying SST (Small et al, 2008), as assumed in YSU. This may explain the weak vertical wind velocity shear anomalies found in CPLY.

\subsection{Role of the pressure gradient}

In our study, near surface pressure gradient anomalies are weak above fronts (Fig. 11), as described in several observational campaigns (Small et al, 2008). The momentum balance analysis shows that, near the surface, the wind acceleration is mainly due to momentum turbulent mixing and not to pressure gradients. This is consistent with results from idealized studies of Spall (2007b), in the case of strong wind at low latitudes, and Kilpatrick et al (2014) with a comparable experimental framework. Using Large Eddy Simulations, Skyllingstad et al (2006) also showed that the turbulent mixing was the dominant term explaining the wind speed variations. These results contrast with Small et al (2005), Song et al (2006) and Byrne et al (2015) that showed an equilibrium near the surface between advection and pressure gradient, with a negligible contribution of turbulent mixing above fronts. The former examined a frontal structure with much larger spatial and temporal characteristics scales than the mesoscale fronts we considered in our study. The latter two correspond to very different climate conditions. This may explain the discrepancies between their results and ours. Note that O'Neill et al (2010) showed that both turbulent mixing and pressure gradient are important in the surface budget. Nevertheless, their case study presented no capping inversion at the top of the PBL, allowing the pressure gradient anomalies to be maximum near the surface.

In the conceptual framework of LN87, Sea Level Pressure (SLP) gradient anomalies are proportional to SST gradient anomalies (with opposite signs) but can be compensated by the so-called back-pressure effect, related to air temperature modifications. The pressure anomaly at a height $\mathrm{Z}$ is considered inversely proportional to the integral of the temperature anomaly between $\mathrm{Z}$ and the top of the PBL. Above warm SST anomalies, the pressure decrease, due to air warming, is attenuated by the PBL thickening (that induces a pressure increase). The symmetric occurs for cold SST anomalies. In a situation of air temperature inversion, the back-pressure effect can be largely strengthened as shown by Hashizume et al (2002) in the EEP. Above warm SST anomalies, the inversion height $\left(Z_{0}\right)$ increase leads to an air temperature decrease (Fig. 14a) and, thus, positive pressure 
anomalies in the upper part of the PBL. These anomalies compensate the pressure decrease created by air warming in the lower PBL leading, overall, to much weaker SLP anomalies than expected in LN87 framework. Again, the symmetrical situation is obtained above cold SST anomalies. Note that, according to Small et al (2008), this effect requires relatively weak winds so that the SST gradient influence can reach the temperature inversion above the frontal zone.

The PCS presents a strong temperature inversion near 600 m (Fig. 14b for July 2007). Following Small et al (2008), the length scale of the thermal adjustment is $L_{p}=\frac{V_{1} h^{2}}{K_{T}}$. With $V_{1} \sim 7 \mathrm{~m} \mathrm{~s}^{-1}, \mathrm{~h} \sim 600 \mathrm{~m}$ and $K_{T} \sim 40 \mathrm{~m}^{2}$ $\mathrm{s}^{-1}, L_{p} \sim 63 \mathrm{~km}$, which is smaller than the typical frontal zone length $(\sim 100 \mathrm{~km})$ considered here. This suggests that a strong back-pressure effect could exist over mesoscale fronts in the region. To examine this mechanism, vertical profiles of temperature anomalies are plotted on Figure $14 \mathrm{c}^{3}$. Warm (cold) SST anomalies induce warm (cold, respectively) air temperature anomalies below $Z_{0}$ and cold (warm) air temperature anomalies above (Figure 14c), as described in Hashizume et al (2002). Consequently, SST gradients create downwind pressure gradients of the same sign in the upper PBL (Fig. 11a and c). These pressure gradients accelerate (decelerate) the wind in the upper layers when it flows above warm to cold (cold to warm, respectively) fronts. Below, their intensity decreases, resulting in very little influence of the pressure on the surface flow. Kilpatrick et al (2014) also showed that low SLP gradients above SST fronts are due to a back-pressure effect following Hashizume et al (2002)'s mechanism.

Note that besides their weak influence above fronts, SLP gradient anomalies seem to play an important role away from the SST gradient zone, where it acts to equilibrate the turbulent mixing and maintain the wind anomalies (not shown). This is consistent with Spall (2007b), nevertheless this analysis is beyond the scope of the present study.

\footnotetext{
3 SST anomalies creates $10 \mathrm{~m}$ temperature anomalies that are advected slightly downwind of the SST anomalies (not shown). Thus, the air temperature anomalies vertical profiles (Fig. 14c) are normalized with the 10-m air temperature anomalies values rather the SST values.
} 
5.3 About the relation between WS divergence and SST Laplacian

In the present work, we examine the relation between WS and SST mesoscale fields (1) and its two derived relations (5) and (6). However, another relation has been identified by Minobe et al (2008) in the Kuroshio region:

$$
\operatorname{div}\left({\overrightarrow{v_{1}}}^{\prime}\right) \propto \operatorname{div}\left(\overrightarrow{\operatorname{grad}}\left(S S T^{\prime}\right)\right)=\vec{\nabla}^{2}\left(S S T^{\prime}\right)
$$

Relation (13) has also been found in idealized simulations with very weak background wind conditions (Lambaerts et al, 2013). In our region, we find correlation associated to (13) much weaker than for relations (1), (5) and (6) (not shown).

While several mechanisms have been invoked to relation (1), Minobe et al (2008) proposed a mechanism to explain (13) based only on pressure anomalies. Following LN87, they consider the vertically averaged momentum balance in the PBL, approximating the PBL wind velocity and pressure by surface fields and considering the surface pressure anomalies proportional to the SST anomalies. These are strong hypothesis: O'Neill et al (2010) and Kilpatrick et al (2014) showed large differences between PBL-integrated and surface fields. Also, Brachet et al (2012) and Piazza et al (2015) noticed that SLP anomalies are not proportional to SST anomalies but to verticaly integrated air temperature anomalies. Thus, a strong back-pressure effect as in our region (Sec.5.2) could lead to a very weak relation between SST and SLP anomalies. Another reason for not finding clear evidence for (13) in our case may be because the focus is on the PBL response to mesoscale structures evolving in time while Minobe et al (2008) used 4 years-averaged fields. Brachet et al (2012) showed indeed different atmospheric responses to the SST when considering long-term mean or 10-day mean fields.

It is important to note that (1) and (13) describe two different relations between SST and WS mesoscale fields but they do not reveal the underlying mechanisms. Indeed, Minobe et al (2008) explains (13) by a process based only on pressure anomalies while (1) is explained by several processes (see Sec. 1), among which pressure anomalies. 


\section{Summary and conclusions}

Using satellite observations and a high resolution ocean-atmosphere coupled model, correlated patterns between mesoscale SST and WS intensity in the PCS are evidenced. Spatial and seasonal variations of the coupling strength, measured as the regression between WS intensity and SST anomalies, bear noticeable similarities in model simulations and observations. In particular, there is an important seasonal variability, the mesoscale coupling being much stronger in winter than in summer. Spatial variations seem to be related to large-scale fields such as the surface wind steadiness and mean speed. An in-depth analysis of dynamical processes in the atmospheric PBL shows that the stress increase (decrease) above warm (cold) SST anomalies is primarily due to an enhanced (weakened) turbulent kinetic energy. It is partially counterbalanced by the wind velocity shear decrease (increase) over warm (cold) SST anomalies, associated to vertical mixing. Using a downwind momentum budget, we show that the wind velocity shear anomalies are mainly caused by the momentum turbulent mixing in frontal regions. Pressure gradient anomalies are negligible near the surface in frontal regions because of a backpressure effect related to air temperature inversion. Comparing austral summer and winter, the WS response is twice as strong in winter as in summer because the large-scale wind shear (larger in winter) makes the action of the turbulent stress more efficient.

The described mechanisms at work in the PCS region may be different in other regions. Indeed the back pressure effect is expected to be much lower in unstable regions without temperature inversion. In addition, as underlined by Spall (2007b), the momentum balance depends on the latitude with stronger Coriolis effect at higher latitude. This could result in stronger wind direction anomalies which may no longer be negligible. Also, as described by Small et al (2008), stonger wind conditions and/or stronger SST gradients could modify the equilibrium above frontal regions, as the air column has less time to adjust to the SST changes before being advected. Finally, the coupling mechanisms may depend on the size of the mesoscale structures (Byrne et al, 2015) that can vary geographically.

In this study we focus on the PBL response to SST anomalies in the PCS. The impact of mesoscale SSTinduced WS intensity anomalies on the ocean dynamics is not addressed. Mesoscale surface currents also alter 
surface wind by friction (see Sec. 2.2.1). WS intensity and WS curl anomalies, generated through these effects, can largely impact ocean eddies (e.g. Jin et al, 2009) and Ekman pumping intensity (Gaube et al, 2015). Mesoscale air-sea coupling may also induces a thermal damping of eddies (Shuckburgh et al, 2010; Kirtman et al, 2012). In the PCS, and more generally in EBUS, the ocean mesoscale eddy activity plays an important role in the system functioning. Eddy advection is an important part of heat and momentum balance (e.g. Colas et al, 2012, 2013). Eddies are also important for the ecosystem as they drive a spatial redistribution of the upwelled nutrients and planktons (e.g. Lathuilière et al, 2010; Bertrand et al, 2014). Thus, ocean-atmosphere interactions at mesoscale may have a role on the dynamics and biological activity in EBUS and its importance is still to be fully elucidated.

Acknowledgements This work is part of V. Oerder's PhD thesis, sponsored by the Ministère de l'Enseignement Supérieur et de la Recherche. It is also part of the ANR project "PULSATION-11-MONU-010" and the LEFE/GMMC project "NEMPECH". Simulations were performed on the supercomputer Curie from the GENCI at the CEA (projects 2011040542, 2012061047 and 2014102286). The authors want to thank Francoise Pinsard and Eric Maisonnave for their help in setting-up the coupled model NEMO-OASIS-WRF and Guillaume Samson, Hervé Giordani and Patrick Marchesiello for useful discussions. F. Lemarié acknowledges the support of the French LEFE/GMMC program through project SIMBAD QSCAT WS data were provided by the CERSAT and are available online at ftp://ftp.ifremer.fr/ifremer/cersat/products/gridded/mwf-quikscat/data/. Microwave OI SST data are produced by Remote Sensing Systems and sponsored by National Oceanographic Partnership Program (NOPP), the NASA Earth Science Physical Oceanography Program, and the NASA MEaSUREs DISCOVER Project. Data are available at www.remss.com. Shortwave radiation from the ISCCP are available in the Objectively Analyzed air-sea Fluxes data and can be downloaded at http://oaflux.whoi.edu/. VOCALS-REx wind data are available online at ftp://precip.meas.ncsu.edu/pub/vocals/. Numerical data were obtained by model experiments described in Sec. 2. Contact the corresponding author for more information (vera.oerder@locean-ipsl.upmc.fr). 


\section{Appendix : Double time averaging of the momentum balance}

The mechanisms driving the feedback of the SST anomalies on the wind speed are investigated. Monthly mean wind speed anomalies $\langle V\rangle^{\prime}$, proportional to the monthly mean SST anomalies $\langle S S T\rangle^{\prime}$, are observed in our simulation (with primes marking the mesoscale anomalies and \langle\rangle the temporal average). We want to identify the dominant mechanism that creates $\langle V\rangle^{\prime}$. In this appendix, we explain why a simple time averaging of a momentum balance does not explain the mean wind speed. Then we present the double time averaging that should be used. It is similar to the one included in the NEMO code (Madec, 2008).

A simple time-average of 1D momentum balance:

$$
\partial_{t} V=\sum_{F_{n} \in\{\text { Forces }\}} F_{n}
$$

relates the forcing time average to the difference between the final and initial wind speed but not to the average wind speed $\langle V\rangle$, which is the variable of interest :

$$
\sum_{F_{n} \in\{\text { Forces }\}}\left\langle F_{n}\right\rangle=\left\langle\partial_{t} V\right\rangle=\left\langle\frac{\Delta V}{\Delta t}\right\rangle=\frac{V(0)-V\left(N_{\text {step }}\right)}{\Delta t}
$$

with $V(p)$, the wind speed p time steps after the beginning of the month, $N_{\text {step }}$ the number of time steps during July, $\Delta t$ the time step duration, and $\Delta V=V(p)-V(p-1)$ the wind speed difference between 2 time steps.

The monthly mean wind speed is $\langle V\rangle=\frac{1}{N_{\text {step }}+1} \sum_{p=0}^{N_{\text {step }}} V(p)$ and $V(p)$ can be expressed using the initial conditions $V(0): V(p)=V(0)+\sum_{k=1}^{p} \Delta V$, so, we obtain :

$$
\begin{aligned}
\langle V\rangle & =\frac{1}{N_{\text {step }}+1} \sum_{p=0}^{N_{\text {step }}}\left(V(0)+\sum_{k=1}^{p} \Delta V\right) \\
& =V(0)+\frac{1}{N_{\text {step }}+1} \sum_{p=0}^{N_{\text {step }}}\left(\sum_{k=1}^{p} \Delta V\right)
\end{aligned}
$$


We introduce a new metric $\lceil F\rceil$, the double time averaging of a quantity $\mathrm{F}$, defined as :

$$
\lceil F\rceil=\frac{1}{N_{\text {step }}+1} \sum_{p=0}^{N_{\text {step }}}\left(\sum_{k=1}^{p} F\right)
$$

${ }_{601}(16)$ can be written $\langle V\rangle=V(0)+\lceil\Delta V\rceil$, i.e.

$$
\frac{\langle V\rangle-V(0)}{\Delta t}=\left\lceil\frac{\Delta V}{\Delta t}\right\rceil
$$

$\left.{ }_{602}^{\lceil}\right\rceil$is a linear operator, so, using (14), we obtain :

$$
\frac{\langle V\rangle-V(0)}{\Delta t}=\left\lceil\frac{\Delta V}{\Delta t}\right\rceil=\left\lceil\partial_{t} V\right\rceil=\sum_{F_{n} \in\{\text { Forces }\}}\left\lceil F_{n}^{\prime}\right\rceil
$$
of $\left\lceil F_{n}\right\rceil$ indicates the dominant mechanisms. 


\section{References}

Adcroft A, Hill C, Marshall J (1997) Representation of topography by shaved cells in a height coordinate ocean model. Mon Wea Rev 125:2293 - 2315, doi: 10.1175/1520-0493(1997)125<2293:ROTBSC>2.0.CO;2

Benshila R, Durand F, Masson S, Bourdallé-Badie R, de Boyer Montégut C, Papa F, Madec G (2014) The upper bay of Bengal salinity structure in a high-resolution model. Ocean Model 74:36-52, doi : 10.1016/j.ocemod.2013.12.001

Bertrand A, Grados D, Colas F, Bertrand S, Capet X, Chaigneau A, Vargas G, Mousseigne A, Fablet R (2014) Broad impacts of fine-scale dynamics on seascape structure from zooplankton to seabirds. Nat Commun 5:5239, doi : 10.1038/ncomms6239

Blanke B, Delecluse P (1993) Variability of the Tropical Atlantic ocean simulated by a general circulation model with two different mixed layer physics. J Phys Oceanogr 23:1363-1388, doi : 10.1175/15200485(1993)023<1363:VOTTAO > 2.0.CO;2

Boe J, Hall A, Colas F, McWilliams J, Qu X, Kurian J, Kapnick S (2011) What shapes mesoscale wind anomalies in coastal upwelling zones ? Clim Dyn 36:2037-2049, doi : 10.1007/s00382-011-1058-5

Bourras D, Reverdin G, Giordani H, Caniaux G (2004) Response of the atmospheric boundary layer to a mesoscale oceanic eddy in the northeast atlantic. J Geophys Res 109:D18,114, doi : 10.1029/2004JD004799

Brachet S, Codron F, Feliks Y, Ghil M, Treut HL, Simonnet E (2012) Atmospheric circulations induced by a midlatitude SST front: A GCM study. J Clim 25:1847-1853, doi : 10.1175/JCLI-D-11-00329.1

Bryan FO, Tomas R, Dennis JM, Chelton DB, Loeb NG, McClean JL (2010) Frontal scale air-sea interaction in high-resolution coupled climate models. J Clim 23:6277-6291, doi : 10.1175/2010JCLI3665.1

Businger J, Shaw W (1984) The response of the marine boundary layer to mesoscale variations in sea-surface temperature. Dyn Atmos Oceans 8:267-281, doi : 10.1016/0377-0265(84)90012-5

Byrne D, Papritz L, Frenger I, Münnich M, Gruber N (2015) Atmospheric response to mesoscale sea surface temperature anomalies: Assessment of mechanisms and coupling strength in a high-resolution coupled model over the South Atlantic. J Atmos Sci 72:1872-1890, doi : 10.1175/JAS-D-14-0195.1 
Capet X, Colas F, Penven P, Marchesiello P, McWilliams J (2008) Eddies in eastern-boundary subtropical upwelling systems. AGU Monograph 177:131-147, doi : 10.1029/177GM10

Castelao R (2012) Sea surface temperature and wind stress curl variability near a cape. J Phys Oceanogr 42:2073-2087, doi : 10.1175/JPO-D-11-0224.1

CERSAT (2002) Mean wind fields (MWF product)-user manual-volume1: Quikscat. C2-MUT-W-04-IF. CERSAT-IFREMER Http://www.ifremer/cersat.fr

Chelton DB, Esbensen SK, Schlax MG, Thum N, Freilich MH, Wentz FJ, Gentemann CL, McPhaden MJ, Schopf PS (2001) Observations of coupling between surface wind stress and sea surface temperature in the Eastern Tropical Pacific. J Clim 14:1479-1498, doi : 10.1175/1520-0442(2001)014<1479:OOCBSW>2.0.CO;2 Chelton DB, Schlax MG, Freilich MH, Milliff RF (2004) Satellite measurements reveal persistent small-scale features in ocean winds. Science 303:978-983, doi : 10.1126/science.1091901

Chelton DB, Schlax MG, Samelson RM (2007) Summertime coupling between sea surface temperature and wind stress in the California Current System. J Phys Oceanogr 37:495-517, doi : 10.1175/JPO3025.1

Chen F, Dudhia J (2001) Coupling an advanced land surface-hydrology model with the penn state-NCAR MM5 modeling system. part ii: Preliminary model validation. Mon Weather Rev 129(4):587-604, doi : 10.1175/15200493(2001)129<0587:CAALSH > 2.0.CO;2

Chou M, Suarez MJ (1994) An efficient thermal infrared radiation parameterization for use in general circulation models. NASA Tech Memo p 84

Colas F, McWilliams JC, Capet X, Kurian J (2012) Heat balance and eddies in the Peru-Chile current system. Clim Dyn 39(1-2):509-529, DOI 10.1007/s00382-011-1170-6

Colas F, Capet X, McWilliams JC, Li Z (2013) Mesoscale eddy buoyancy flux and eddy-induced circulation in Eastern Boundary Currents. J Phys Oceanogr 43:1073-1095, doi : 10.1175/JPO-D-11-0241.1

Davey M, et al (2002) STOIC: a study of coupled model climatology and variability in tropical ocean regions. Clim Dyn 18(5):403-420, doi 10.1007/s00382-001-0188-6

Dawe JT, Thompson L (2006) Effect of ocean surface currents on wind stress, heat flux, and wind power input to the ocean. Geophys Res Lett 33:L09,604, doi : 10.1029/2006GL025784 
De Szoeke SP, Fairall CW, Wolfe DE, Bariteau L, Zuidema P (2010) Surface flux observations in the Southeastern Tropical Pacific and attribution of SST errors in coupled ocean-atmosphere models. J Clim 23:4152-4174, doi : 10.1175/2010JCLI3411.1

De Szoeke SP, Yuter S, Mechem D, Fairall CW, Burleyson CD, Zuidema P (2012) Observations of stratocumulus clouds and their effect on the Eastern Pacific surface heat budget along $20^{\circ}$ s. J Clim 25:8542-8567, doi : 10.1175/jcli-d-11-00618.1.

Dee DP, et al (2011) The ERA-interim reanalysis: configuration and performance of the data assimilation system.

Q J R Meteorol Soc 137:553-597, doi : 10.1002/qj.828

Desbiolles F, Blanke B, Bentamy A (2014) Short-term upwelling events at the Western African coast related to synoptic atmospheric structures as derived from satellite observations. J Geophys Res Oceans 119:461-483, doi : 10.1002/2013JC009278

Dunbar R, Lungu T, Weiss B, Stiles B, Huddleston J, Callahan P, Shirtliffe G, Perry K, Hsu C, Mears C, Wentz F, Smith D (2006) QuikSCAT science data product user manual, version 3.0. JPL Document D-18053 - Rev A Jet Propulsion Laboratory, Pasadena, CA

Dussin R, Treguier AM, Molines JM, Barnier B, Penduff T, Brodeau L, Madec G (2009) Definition of the interannual experiment ORCA025-B83, 1958-2007. Tech. rep., LPO-09-02

Farrow DE, Stevens DP (1995) A new tracer advection scheme for Bryan and Cox type ocean general circulation models. J Phys Oceanogr 25:1731-1741, doi : 10.1175/1520-0485(1995)025<1731:ANTASF $>2.0 . C O ; 2$

Frenger I, Gruber N, Knutti R, Münnich M (2013) Imprint of Southern Ocean eddies on winds, clouds and rainfall. Nat Geosci 6:608-612, doi : 10.1038/ngeo1863

Gaube P, Chelton DB, Samelson RM, Schlax MG, O'Neill LW (2015) Satellite observations of mesoscale eddyinduced Ekman pumping. J Phys Oceanogr 45:104-132, doi : 10.1175/JPO-D-14-0032.1

Giordani H, Planton S, Benech B, Kwon BH (1998) Atmospheric boundary layer response to sea surface temperatures during the SEMAPHORE experiment. J Geophys Res 103(C11):25,047-25,060, doi : 10.1029/98JC00892

Gruber N, Lachkar Z, Frenzel H, Marchesiello P, Münnich M, McWilliams JC, Nagai T, Plattner GK (2011) Eddy-induced reduction of biological production in Eastern Boundary Upwelling Systems. Nat Geosci 
4:787-792, doi : 10.1038/ngeo1273

Hashizume H, Xie SP, Fujiwara M, Tanimoto TWY (2002) Direct observations of atmospheric boundary layer response to SST variations associated with tropical instability waves over the Eastern Equatorial Pacific. J Clim 15:3379-3393, doi : 10.1175/1520-0442(2002)015<3379:DOOABL >2.0.CO;2

Hayes S, McPhaden M, Wallace J (1989) The influence of sea surface temperature on surface wind in the Eastern Equatorial Pacific: weekly to monthly variability. J Clim 2:1500-1506, doi : 10.1175/15200442(1989)002<1500:TIOSST > 2.0.CO;2

Hogg A, Dewar WK, Berloff P, Kravtsov S, Hutchinson DK (2009) The effects of mesoscale ocean-atmosphere coupling on the large-scale ocean circulation. J Clim 22:4066-408, doi : 10.1175/2009JCLI2629.1

Hong S, Lim J (2006) The WRF single-moment 6-class microphysics scheme (WSM6). J Korean Meteorol Soc $42(2): 129-151$

Hong S, Yign N, Jimy D (2006) A new vertical diffusion package with an explicit treatment of entrainment processes. Mon Wea Rev 134:2318-2341, doi : 10.1175/MWR3199.1

Hong SY, Pan HL (1996) Nonlocal boundary layer vertical diffusion in a medium-range forecast model. Mon Wea Rev 124:2322-2339, doi : 10.1175/1520-0493(1996)124<2322:NBLVDI >2.0.CO;2

Hu XM, J W NG, F Z (2010) Evaluation of three planetary boundary layer schemes in the WRF model. J Appl Meteor Climatol 49:1831-1844, doi : 10.1175/2010JAMC2432.1

Janjic ZI (1994) The step-mountain eta coordinate model: Further developments of the convection, viscous sublayer, and turbulence closure schemes. Mon Wea Rev 122:927-945, doi : 10.1175/15200493(1994)122<0927:TSMECM >2.0.CO;2

Jin X, Dong C, Kurian J, McWilliams JC, Chelton DB, Li Z (2009) SST-wind interaction in coastal upwelling: Oceanic simulation with empirical coupling. J Phys Oceanogr 39:2957-2970, doi : 10.1175/2009JPO4205.1 Jouanno J, Sheinbaum J (2013) Heat balance and eddies in the Caribbean upwelling system. J Phys Oceanogr 43:1004-1014, doi : 10.1175/JPO-D-12-0140.1

Kilpatrick T, Schneider N, Qiu B (2014) Boundary layer convergence induced by strong winds across a midlatitude SST front. J Clim 27:1698-1718, doi : 10.1175/JCLI-D-13-00101.1 
Kirtman BP, et al (2012) Impact of ocean model resolution on CCSM climate simulations. Clim Dyn 39:1303-1328, doi : 10.1007/s00382-012-1500-3

Koseki S, Watanabe M (2010) Atmospheric boundary layer response to mesoscale SST anomalies in the Kuroshio extension. J Clim 23:2492-2507, doi : 10.1175/2009JCLI2915.1

Lambaerts J, Lapeyre G, Plougonven R, Klein P (2013) Atmospheric response to sea surface temperature mesoscale structures. J Geophys Res Atmos 118:9611-9621, doi : 10.1002/jgrd.50769

Lathuilière C, Echevin V, Lévy M, Madec G (2010) On the role of the mesoscale circulation on an idealized coastal upwelling ecosystem. J Geophys Res 115:C09,018, doi : 10.1029/2009JC005827

Lemarié F (2015) Numerical modification of atmospheric models to include the feedback of oceanic currents on air-sea fluxes in ocean-atmosphere coupled models. Technical Report RT-464, INRIA Grenoble - Rhône-Alpes, https://hal.inria.fr/hal-01184711/file/RT-464.pdf

Lindzen R, Nigam S (1987) On the role of sea surface temperature gradients in forcing low level winds and convergence in the Tropics. J Atmos Sci 44:2418-2436, doi : 10.1175/1520-0469(1987)044<2418:OTROSS>2.0.CO;2

Liu W, Zhang A, Bishop J (1994) Evaporation and solar irradiance as regulators of sea surface temperature in annual and interannual changes. J Geophys Res 99:12,623-12,637, doi : 10.1029/94JC00604

Lévy M, Estubier A, Madec G (2001) Choice of an advection scheme for biogeochemical models. Geophys Res Let 28:3725-3728, doi : 10.1029/2001GL012947

Ma CC, Mechoso C, Robertson A, Arakawa A (1996) Peruvian stratus clouds and Tropical Pacific circulation: a coupled ocean-atmosphere (GCM) study. J Clim 9:1635-1645, doi : 10.1007/s00382-008-0407-5

Madec G (2008) NEMO ocean engine. Note du Pole de modélisation, Institut Pierre-Simon Laplace (IPSL) 27:ISSN No $1288-1619$

Maloney ED, Chelton DB (2006) An assessment of the sea surface temperature influence on surface wind stress in numerical weather prediction and climate models. J Clim 19:2743-2762, doi : 10.1175/JCLI3728.1

Meehl GA, Covey C, McAvaney B, Latif M, Stouffer RJ (2005) Overview of the coupled model intercomparison project. Bull Am Meteorol Soc 86:89-93, doi : 10.1175/BAMS-86-1-89 
Minobe S, Kuwano-Yoshida A, Komori N, Xie SP, Small RJ (2008) Influence of the Gulf Stream on the troposphere. Nature 452:206-209, doi : 10.1038/nature06690

Mlawer E, Taubman S, Brown P, Iacono M, Clough S (1997) Radiative transfer for inhomogeneous atmosphere: RRTM, a validated correlated-k model for the long-wave. J Geophys Res 102:16,663-16,682, doi : 10.1029/97JD00237

Monin AS, Obukhov AM (1954) Basic laws of turbulent mixing in the atmosphere near the ground. Tr Inst Teor Geofiz Akad Nauk SSSR 24:1963-1987

Nakanishi M, Niino H (2009) Development of an improved turbulence closure model for the atmospheric boundary layer. J Meteorol Soc Jpn 87:895-912, doi : 10.2151/jmsj.87.895

Oerder V, Colas F, Echevin V, Codron F, Tam J, Belmadani A (2015) Peru-Chile upwelling dynamics under climate change. J Geophys Res Oceans 120(2):1152-1172, DOI 10.1002/2014JC010299

O’Neill L, Chelton D, Esbensen S, Wentz F (2005) High-resolution satellite measurements of the atmospheric boundary layer response to SST variations along the Agulhas return current. J Clim 18:2706-2723, doi : 10.1175/JCLI3415.1

O'Neill LW, Esbensen S, Thum N, Samelson RM, Chelton DB (2010) Dynamical analysis of the boundary layer and surface wind responses to mesoscale SST perturbations. J Clim 23:559-581, doi : 10.1175/2009JCLI2662.1

O'Neill LW, Chelton DB, Esbensen SK (2012) Covariability of surface wind and stress responses to sea surface temperature fronts. J Clim 25:5916-5942, doi : 10.1175/JCLI-D-11-00230.1

Paulson CA (1970) The mathematical representation of wind speed and temperature profiles in the unstable atmospheric surface layer. J Appl Meteor 9:857-861, doi : 10.1175/15200450(1970)009<0857:TMROWS >2.0.CO;2

Penven P, Echevin V, Pasapera J, Colas F, Tam J (2005) Average circulation, seasonal cycle, and mesoscale dynamics of the Peru current system: A modeling approach. J Geophys Res 110:C10,021, doi : 10.1029/2005JC002945

Perlin N, Skyllingstad ED, Samelson RM, Barbour PL (2007) Numerical simulation of air-sea coupling during coastal upwelling. J Phys Oceanogr 37:2081-2093, doi : 10.1175/JPO3104.1 
Perlin N, de Szoeke SP, Chelton DB, Samelson RM, Skyllingstad ED, O'Neill LW (2014) Modeling the atmospheric boundary layer wind response to mesoscale sea surface temperature perturbations. Mon Wea Rev 142:4284-4307, doi : 10.1175/MWR-D-13-00332.1

Piazza M, Terray L, Boé J, Maisonnave E, Sanchez-Gomez E (2015) Influence of small-scale North Atlantic sea surface temperature patterns on the marine boundary layer and free troposphere: a study using the atmospheric ARPEGE model. Clim Dyn pp 1-19, DOI 10.1007/s00382-015-2669-z

Putrasahan DA, Miller A, Seo H (2013) Regional coupled ocean-atmosphere downscaling in the Southeast Pacific: impacts on upwelling, mesoscale air-sea fluxes, and ocean eddies. Ocean Dynam 63:463-488, 10.1007/s10236-013-0608-2

Renault L, Hall A, McWilliams JC (2015) Orographic shaping of US West Coast wind profiles during the upwelling season. Clim Dyn DOI 10.1007/s00382-015-2583-4, doi : 10.1007/s00382-015-2583-4

Resplandy L, Lévy M, Madec G, Pous S, Aumont O, Kumar D (2011) Contribution of mesoscale processes to nutrient budgets in the Arabian sea. J Geophys Res 116:C11,007, doi : 10.1029/2011JC007006

Samelson RM, Skyllingstad ED, Chelton DB, Esbensen SK, O'Neill LW, Thum N (2006) On the coupling of wind stress and sea surface temperature. J Clim 19:1557-1566, doi : 10.1175/JCLI3682.1

Samson G, Masson S, Lengaigne M, Keerthi MG, Vialard J, Pous S, Madec G, Jourdain NC, Jullien S, Menkes C, Marchesiello P (2014) The NOW regional coupled model: Application to the Tropical Indian ocean climate and tropical cyclone activity. J Adv Mod Earth Sys 6(3):700-722, DOI 10.1002/2014MS000324

Schiffer R, Rossow W (1983) The international satellite cloud climatology project ISCCP: The first project of the world climate research programme. Bull Am Meteorol Soc 64:779-784

Shin H, Hong SY (2011) Intercomparison of planetary boundary-layer parametrizations in the WRF model for a single day from CASES-99. Bound-Layer Meteor 139(2):261-281, DOI 10.1007/s10546-010-9583-z

Shuckburgh E, Maze G, Ferreira D, Marshall J, Jones H, Hill C (2010) Mixed layer lateral eddy fluxes mediated by air-sea interaction. J Phys Oceanogr 41:130-144, dOI : 10.1175/2010JPO4429.1

Skamarock W, Klemp J (2008) A time-split nonhydrostatic atmospheric model for weather research and forecasting applications. J Comp Phys 227:3465-3485, doi : 10.1016/j.jcp.2007.01.037 
Skyllingstad ED, Vickers D, Mahrt L, Samelson R (2006) Effects of mesoscale sea-surface temperature fronts on the marine atmospheric boundary layer. Bound-Layer Meteor 123:219-237, doi: 10.1007/s10546-006-9127-8

Small R, deSzoeke S, Xie S, O’Neill L, Seo H, Song Q, Cornillon P, Spall M, Minobe S (2008) Air-sea interaction over ocean fronts and eddies. Dyn Atmos Oceans 45:274-319, doi : 10.1016/j.dynatmoce.2008.01.001

Small RJ, Xie SP, Wang Y, Esbensen SK, Vickers D (2005) Numerical simulation of boundary layer structure and cross-equatorial flow in the Eastern Pacific. J Atmos Sci 62:1812-1830, doi : 10.1175/JAS3433.1

Song Q, Cornillon P, Hara T (2006) Surface wind response to oceanic fronts. J Geophys Res 111:C12,006, doi : 10.1029/2006JC003680

Spall MA (2007a) Effect of sea surface temperature-wind stress coupling on baroclinic instability in the ocean. J Phys Oceanogr 37:1092-1097, doi : 10.1175/JPO3045.1

Spall MA (2007b) Midlatitude wind stress-sea surface temperature coupling in the vicinity of oceanic fronts. J Clim 20:3785-3801, doi : 10.1175/JCLI4234.1

Strub P, Mesias J, Montecino V, Ruttlant J, Salinas S (1998) Coastal ocean circulation off western South America. The Sea vol 11, chap 10:29-67

Sweet W, Fett R, Kerling J, La Violette P (1981) Air-sea interaction effects in the lower troposphere across the north wall of the Gulf Stream. Mon Wea Rev 109:1042-1052, doi : 10.1175/15200493(1981)109<1042:ASIEIT > 2.0.CO;2

Valcke S, Craig T, Coquart L (2013) OASIS3-MCT user guide, OASIS3-MCT 2.0. Tech. rep., CERFACS/CNRS SUC URA No 1875

Wai MK, Stage S (1989) Dynamical analysis of marine atmospheric boundary layer structure near the Gulf Stream oceanic front. Q J R Meteorol Soc 115:29-44, doi : 10.1002/qj.49711548503

Wallace J, Mitchell T, Deser C (1989) The influence of sea surface temperature on surface wind in the Eastern Equatorial Pacific: seasonal and interannual variability. J Clim 2:1492-1499, doi : 10.1175/15200442(1989)002<1492:TIOSST >2.0.CO;2

Webb D, de Cuevas B, Richmond C (1998) Improved advection schemes for ocean models. J Atmos Ocean Technol 15(5):1171-1187, doi : 10.1175/1520-0426(1998)015<1171:IASFOM>2.0.CO;2 
Wood R, et al (2011) The VAMOS ocean-cloud-atmosphere-land study regional experiment (VOCALS-REx): goals, platforms, and field operations. Atmos Chem Phys 11:627-654, doi : 10.5194/acp-11-627-2011

Wyant MC, et al (2010) The PreVOCA experiment: modeling the lower troposphere in the Southeast Pacific. Atmos Chem Phys 10(10):4757-4774, DOI 10.5194/acp-10-4757-2010

Xie SP (2004) Satellite observations of cool ocean-atmosphere interaction. Bull Am Meteorol Soc 85:195-208, doi : 10.1175/BAMS-85-2-195

Zhang YC, Rossow WB, Lacis AA, Oinas V, Mishchenko MI (2004) Fluxes from the surface to top of atmosphere based on ISCCP and other global data sets: refinements of the radiative transfer model and the input data. J Geophys Res 109:D19,105, doi : 10.1029/2003JD004457 


\section{Tables}

\begin{tabular}{|c|c|c|c|c|c|}
\hline & & CPLM & CPLM50 & Observations & CPLY \\
\hline Peru & summer & $0.62(0.59)$ & $0.68(0.61)$ & $0.66(0.52)$ & $0.82(0.61)$ \\
& winter & $1.49(0.77)$ & $1.53(0.81)$ & $1.00(0.59)$ & $1.41(0.73)$ \\
\hline \multirow{2}{*}{ Chile } & summer & $0.27(0.27)$ & $0.28(0.23)$ & $0.26(0.29)$ & $0.39(0.13)$ \\
& winter & $1.13(0.70)$ & $1.14(0.72)$ & $0.92(0.40)$ & $1.22(0.71)$ \\
\hline
\end{tabular}

Table 1: WS-SST mesoscale anomalies Regression Coefficient (RC, in $10^{-2} \mathrm{~N} \mathrm{~m}^{-2}{ }^{\circ} \mathrm{C}^{-1}$ ) off Peru (red box on Fig. 2) and Chile (blue box) during austral summer and winter. $\mathrm{RC}$ are computed using the $1 / 12^{\circ}$ resolution coupled simulations (CPLM and CPLY) fields, CPLM fields regridded to a $50 \mathrm{~km}$ resolution grid (CPLM50), and $50 \mathrm{~km}$ resolution observation fields (QSCAT WS and MW OI SST). Correlations between WS and SST mesoscale anomaly fields are indicated between parenthesis

\begin{tabular}{|c|c|c|c|c|}
\hline & & CPLM & CPLM50 & Observations \\
\hline Peru & summer & $0.86(0.71)$ & $0.98(0.78)$ & $0.9(0.57)$ \\
& winter & $1.45(0.86)$ & $1.68(0.91)$ & $1.26(0.6)$ \\
\hline \multirow{2}{*}{ Chile } & summer & $0.76(0.64)$ & $0.82(0.70)$ & $0.66(0.39)$ \\
& winter & $1.10(0.85)$ & $1.30(0.90)$ & $0.95(0.46)$ \\
\hline
\end{tabular}

Table 2: Same as Table 1 for WS divergence anomalies and downwind gradient of the SST anomalies

\begin{tabular}{|c|c|c|c|c|}
\hline & & CPLM & CPLM50 & Observations \\
\hline Peru & summer & $0.51(0.38)$ & $0.57(0.44)$ & $0.60(0.35)$ \\
& winter & $1.27(0.71)$ & $1.35(0.70)$ & $0.99(0.46)$ \\
\hline Chile & summer & $0.61(0.35)$ & $0.57(0.28)$ & $0.65(0.27)$ \\
& winter & $1.14(0.72)$ & $1.16(0.69)$ & $0.87(0.36)$ \\
\hline
\end{tabular}

Table 3: Same as Table 1 for WS curl anomalies and crosswind gradient of the SST anomalies

\begin{tabular}{|c|c|c|c|}
\hline & January (CPLM) & July (CPLM) & July (CPLY) \\
\hline$\tau_{\text {tur }}^{\prime}$ & 0.45 & 0.70 & 0.76 \\
\hline$\tau_{a}^{\prime}$ & 1.21 & 2.01 & 0.8 \\
\hline$\tau_{b}^{\prime}$ & -0.85 & -1.34 & -0.1 \\
\hline
\end{tabular}

Table 4: RC $\left(10^{-2} \mathrm{~N} \mathrm{~m}-2{ }^{\circ} C^{-1}\right)$ between SST and $\tau_{t u r}, \tau_{a}$ and $\tau_{b}$ anomalies in January and July 2007 for CPLM and July 2007 for CPLY. $\tau_{\text {tur }}$ is the downwind component of the turbulent stress at $20 \mathrm{~m}$. 


\section{Figures}

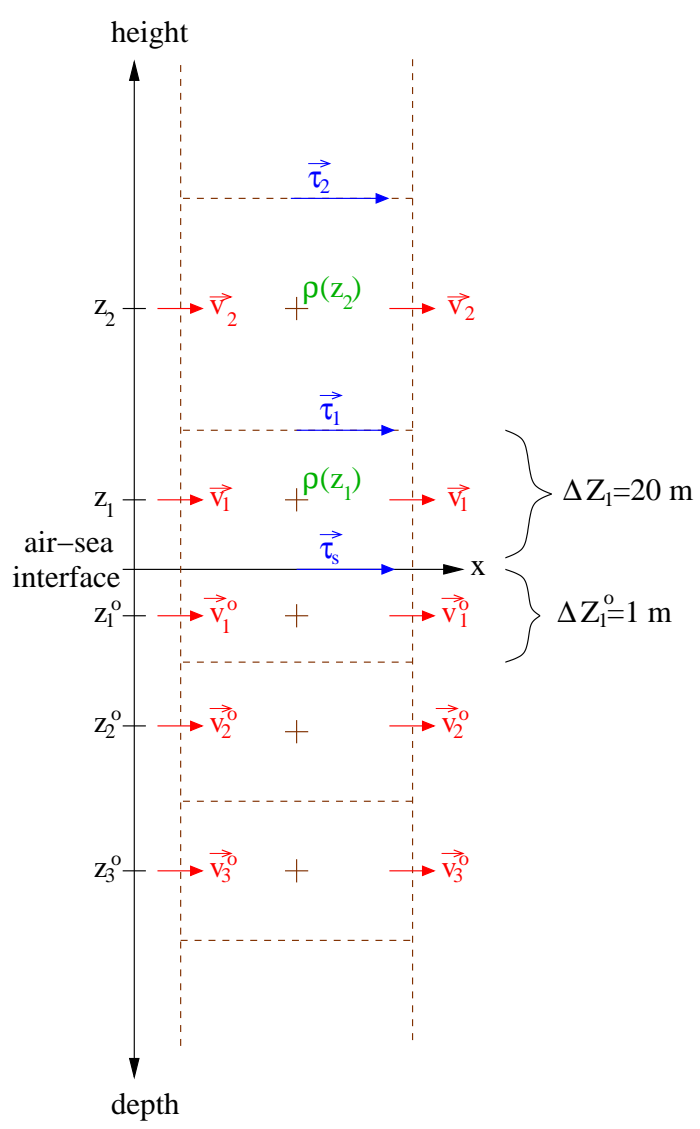

Fig. 1: Vertical structure of the coupled model. Red (blue) vectors represent the model velocities (stress, respectively). $\Delta Z_{1}^{o}\left(\Delta Z_{1}\right)$ is the thickness of the first oceanic (atmospheric, respectively) model layer. $z_{N}\left(z_{N}^{o}\right)$ is the height of atmospheric (oceanic, respectively) level N. $\rho$ is the air density 


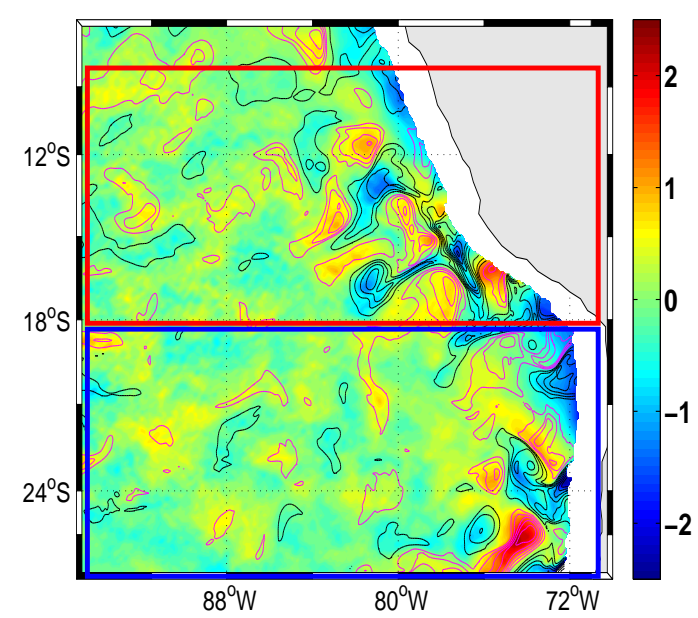

Fig. 2: Surface Wind Stress (WS) mesoscale anomalies (colored, $10^{-2} \mathrm{~N} \mathrm{~m}^{-2}$ ). Sea Surface Temperature (SST) anomalies (contours, ${ }^{\circ} \mathrm{C}$ ) : black (magenta) lines indicate negative (positive, respectively) anomalies, contour interval is $0.25{ }^{\circ} \mathrm{C}$. Fields are from the CPLM simulation and are time-averaged over July 2007. The $150 \mathrm{~km}$ nearshore zone, where the anomalies are dominated by orographic effects, is removed. Anomalies are computed using a gaussian smoothing filter as described in Sec. 2.3.2. Red box indicates the Peru region and the blue box indicates the Chile region
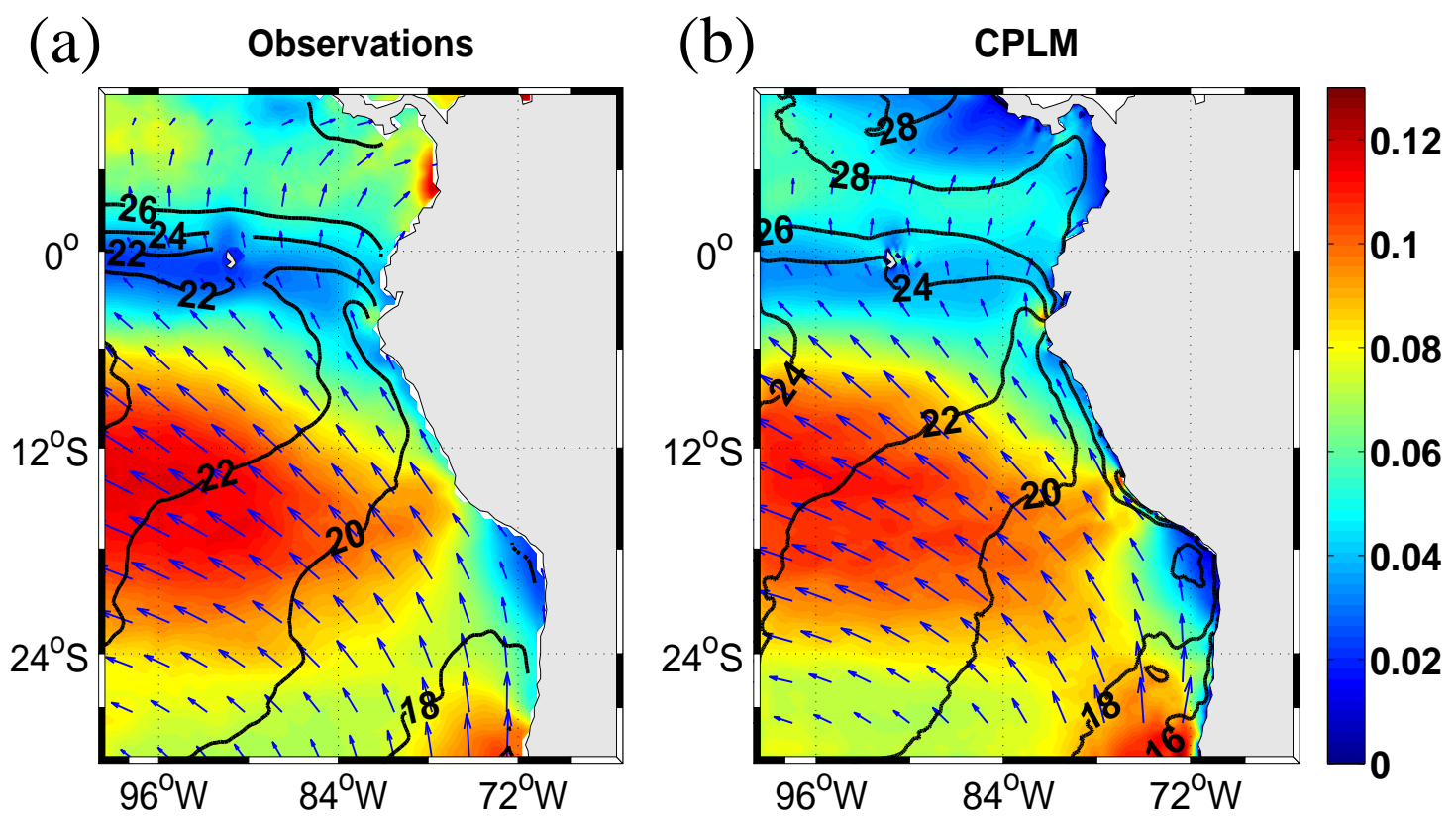

Fig. 3: 2007 annual mean of WS intensity (colored, $\mathrm{N} \mathrm{m}^{-2}$ ), WS direction (blue arrows) and SST (black contours, ${ }^{\circ} \mathrm{C}$ ). Contour interval is $2{ }^{\circ} \mathrm{C}$. (a) Satellite observations and (b) CPLM coupled model simulation 

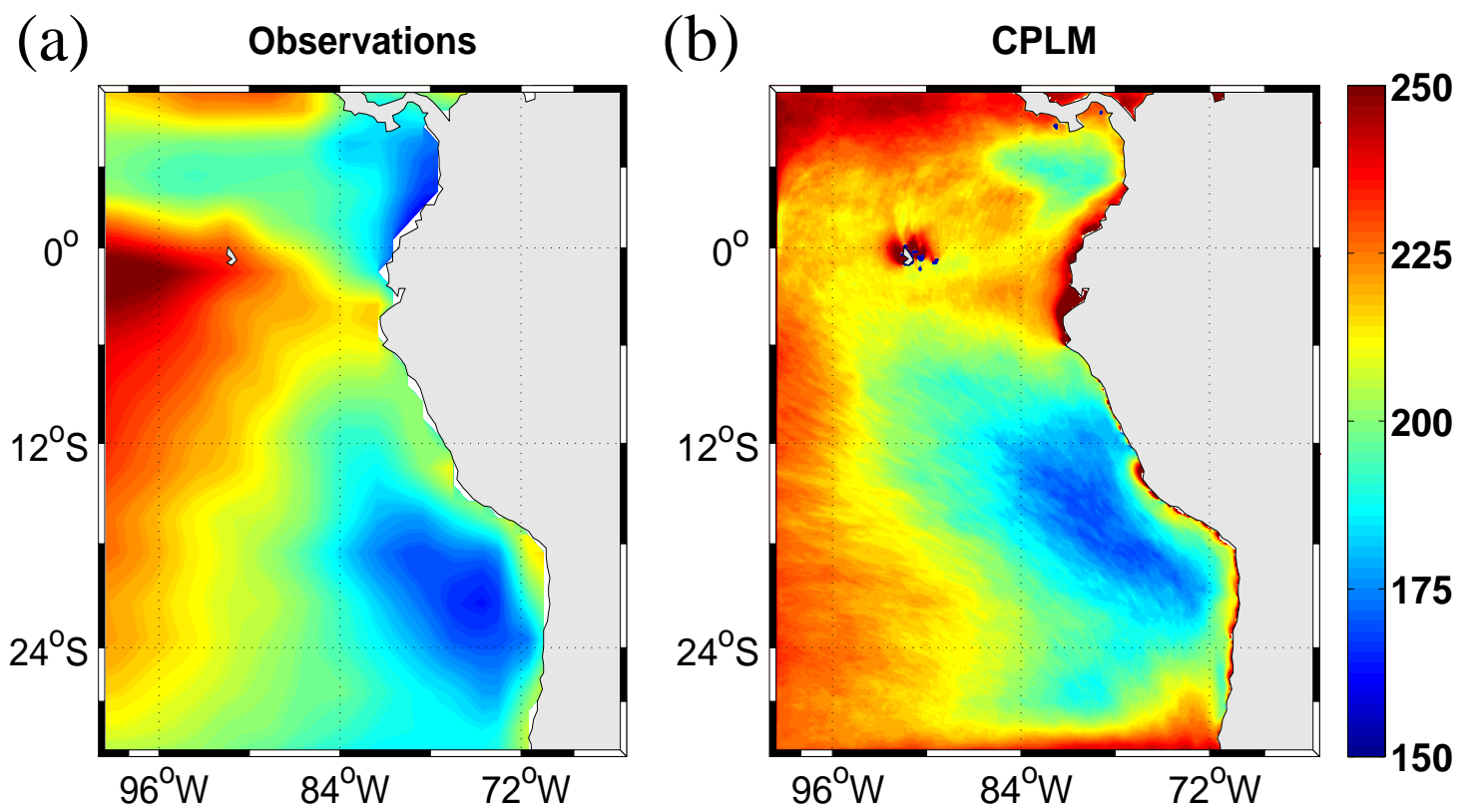

Fig. 4: Short-wave flux at the air-sea interface $\left(\mathrm{W} \mathrm{m}^{-2}, 2007\right.$ annual mean). (a) Satellite observations and (b) CPLM simulation. 
(a)

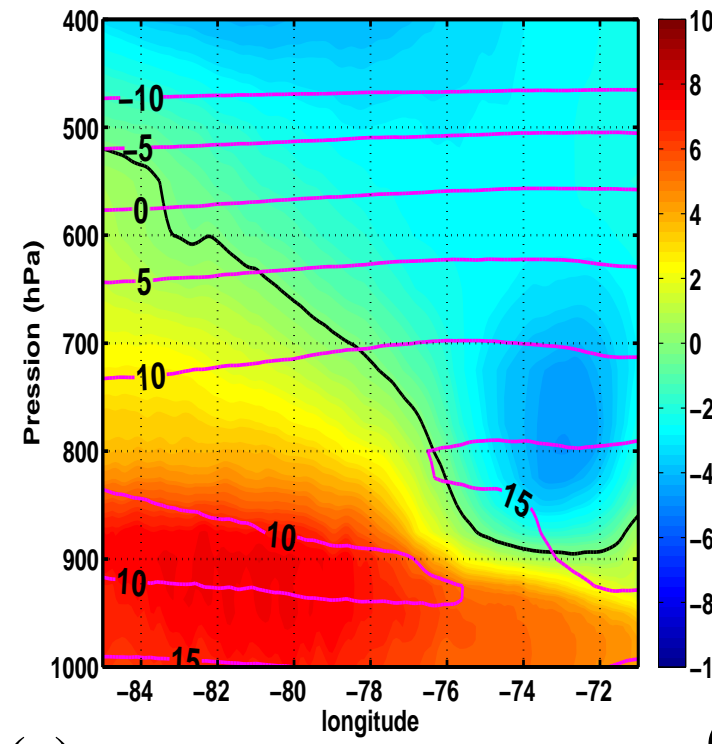

(c)

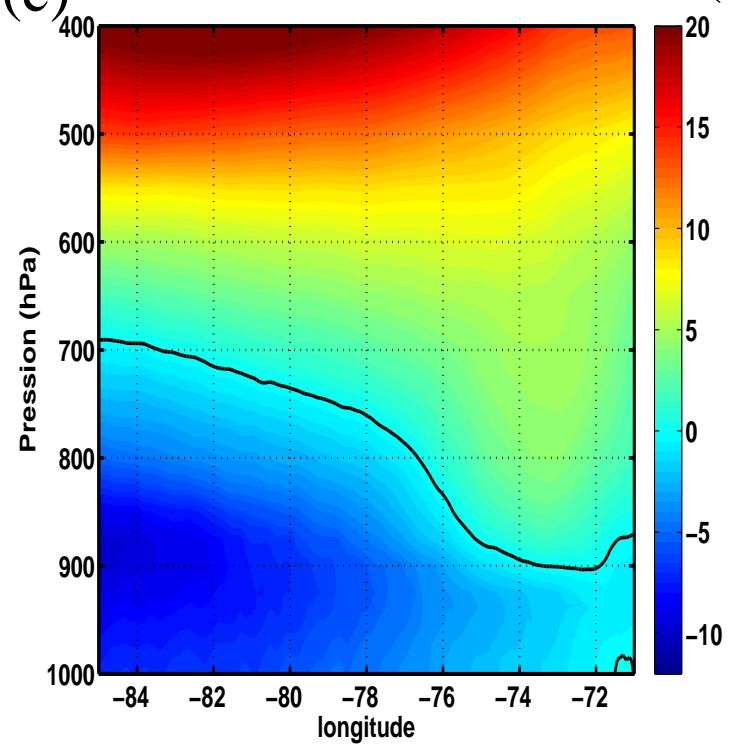

(b)

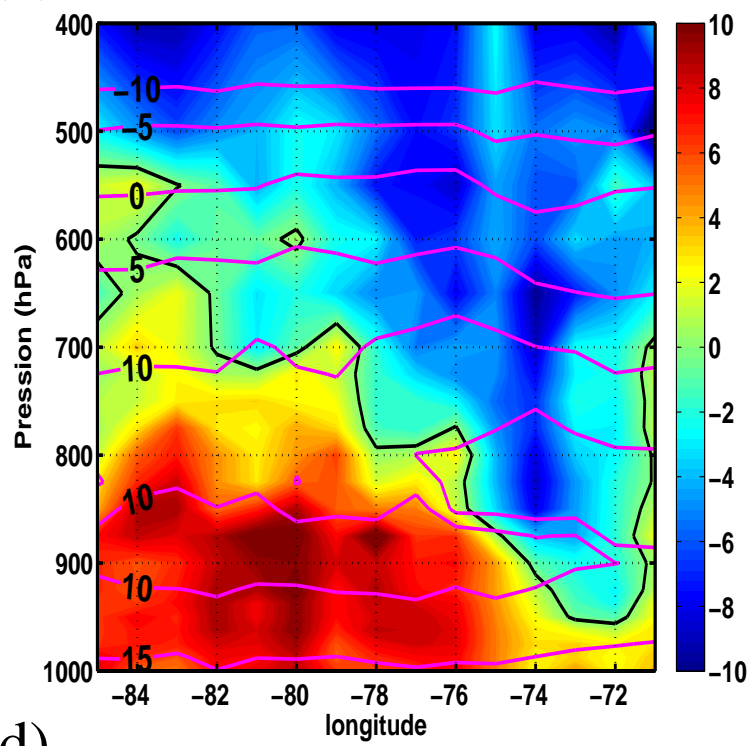

(d)

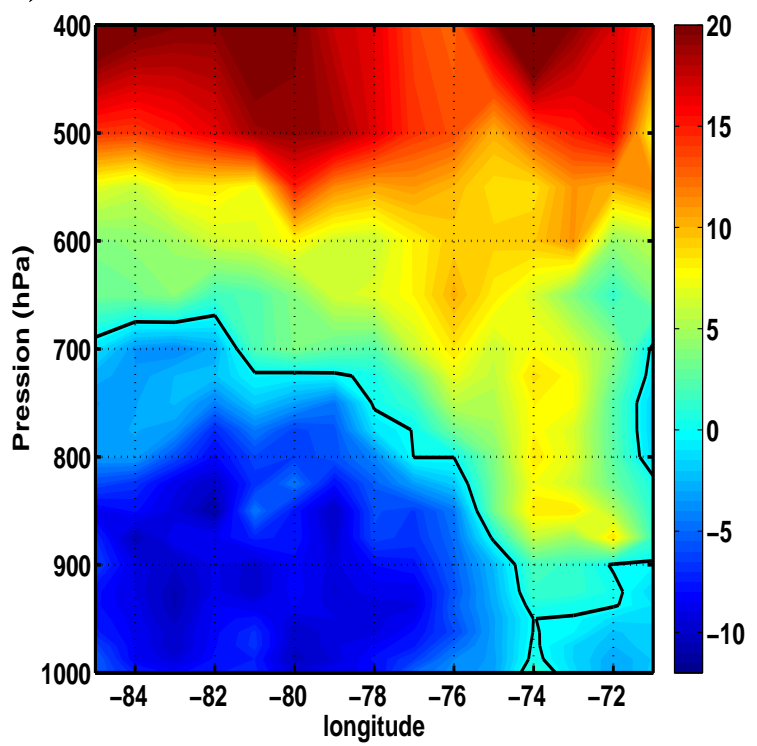

Fig. 5: Zonal sections at $20^{\circ} \mathrm{S}$, time-averaged over the period October, 28 to November, 3 2008. (a) CPLM wind meridional velocity (colored, $\mathrm{m} \mathrm{s}^{-1}$ ) and air temperature (contours in magenta, ${ }^{\circ} \mathrm{C}$, contour interval is $5{ }^{\circ} \mathrm{C}$ ); (b) same as (a) for VOCALS-REx observations; (c) CPLM zonal wind velocity (colored, $\mathrm{m} \mathrm{s}^{-1}$ ); (d) same as (c) for VOCALS-REx observations. Black contours indicate zero velocity. 
(a)

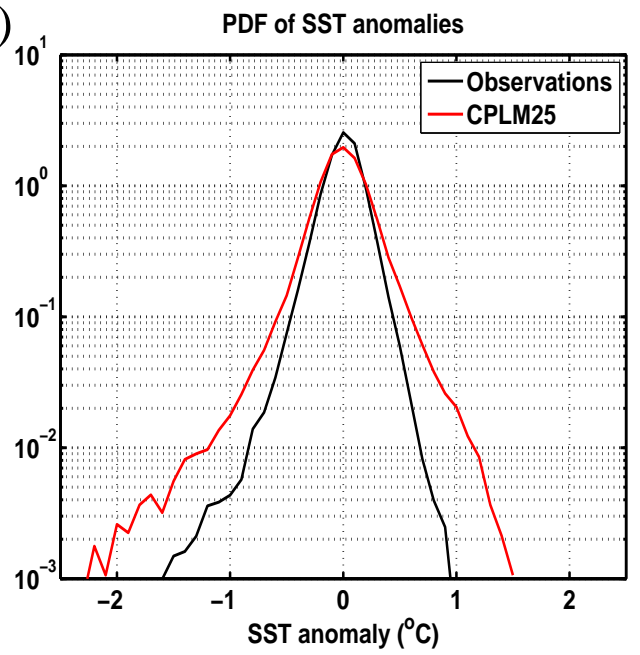

(c)

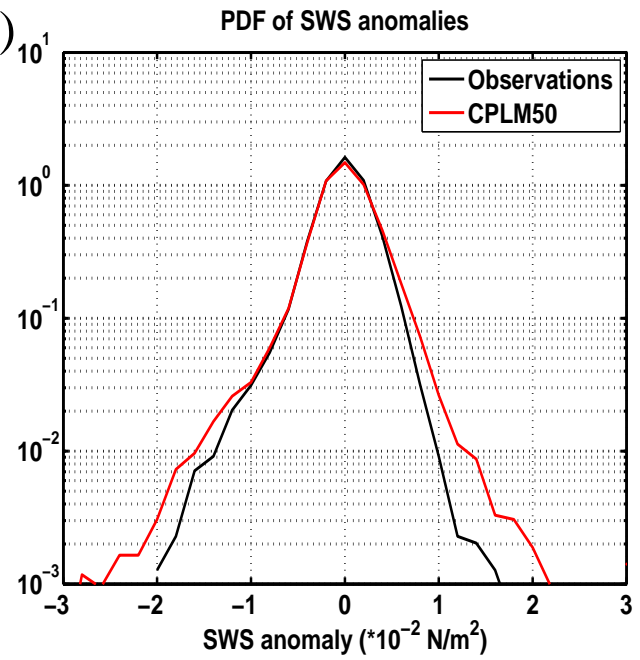

(b)

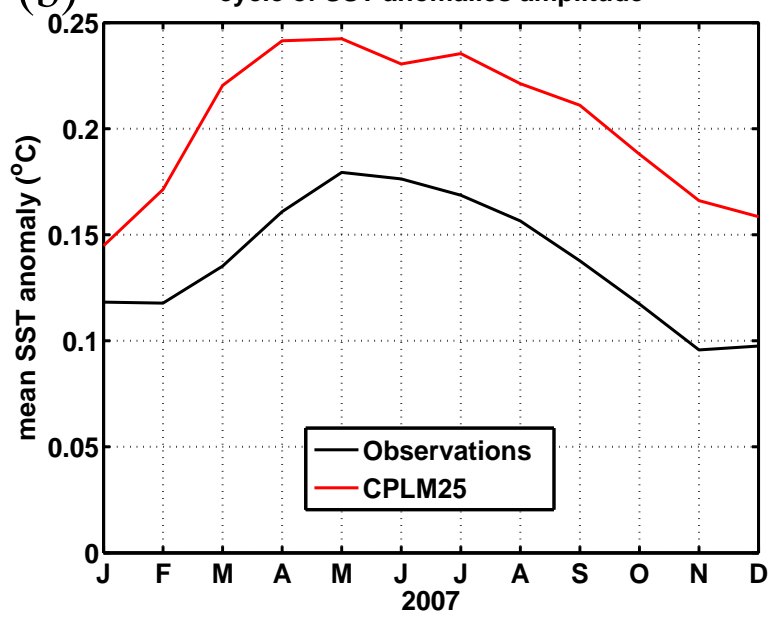

$(\mathrm{d})$

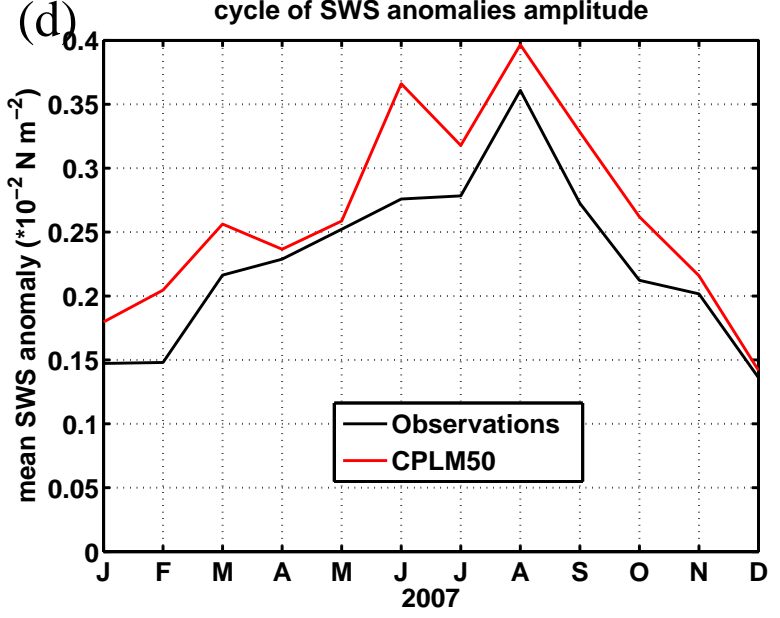

Fig. 6: (a) PDFs of monthly SST anomalies $\left({ }^{\circ} \mathrm{C}\right)$ for 2007; (b) Seasonal cycle of the mean SST anomaly absolute value $\left(2007,{ }^{\circ} \mathrm{C}\right)$; (c) same as (a) for WS anomalies $\left(10^{-2} \mathrm{~N} \mathrm{~m}^{-2}\right)$; (d) same as (b) for the mean WS anomaly absolute value $\left(10^{-2} \mathrm{~N} \mathrm{~m}^{-2}\right)$. Black line is for observations (MW OI $25 \mathrm{~km}$ resolution SST and QSCAT $50 \mathrm{~km}$ resolution WS) and red line is for the CPLM simulation. Anomalies are computed over the $\left[5^{\circ} \mathrm{S}-27^{\circ} \mathrm{S}\right]$ domain. CPLM SST and WS fields are regridded to be compared to the observations (Sec. 2.3.1) 

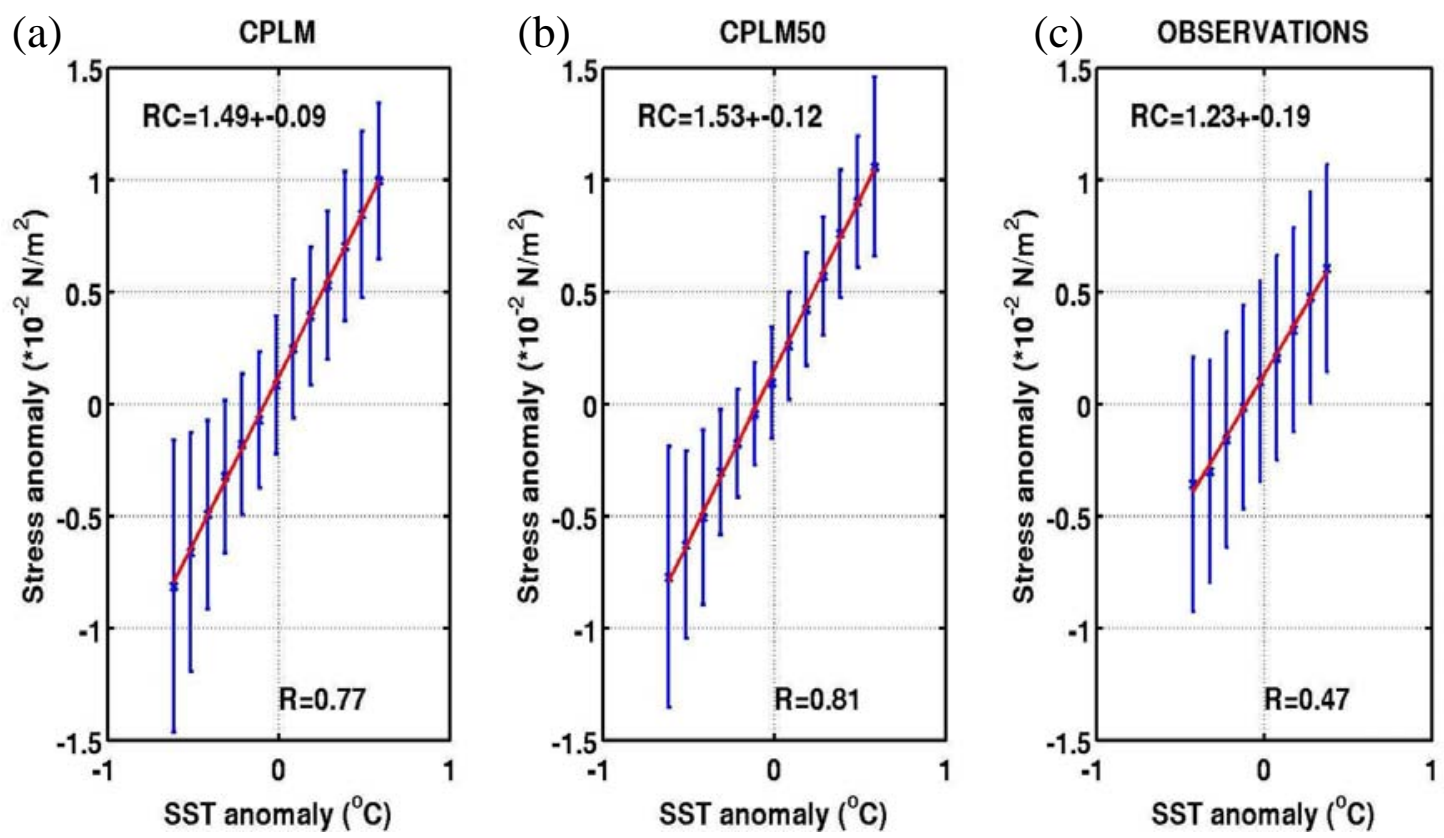

Fig. 7: Binned scatterplot of WS intensity anomalies $\left(10^{-2} \mathrm{~N} \mathrm{~m}^{-2}\right.$ ) with respect to the $\mathrm{SST}$ anomalies $\left({ }^{\circ} \mathrm{C}\right)$ for (a) CPLM, (b) CPLM50 (CPLM fields regridded at $50 \mathrm{~km}$ resolution) and (c) $50 \mathrm{~km}$ resolution observed fields (25 km MW OI SST is regridded at $50 \mathrm{~km}$ resolution). The binned scatterplots are computed for the Peru region following the methodology described in Sec. 2.3 . Correlation (R) and Regression Coefficient (RC, in $10^{-2} \mathrm{~N} \mathrm{~m}^{-2}{ }^{\circ} \mathrm{C}^{-1}$ ) between SST and WS anomalies are indicated.

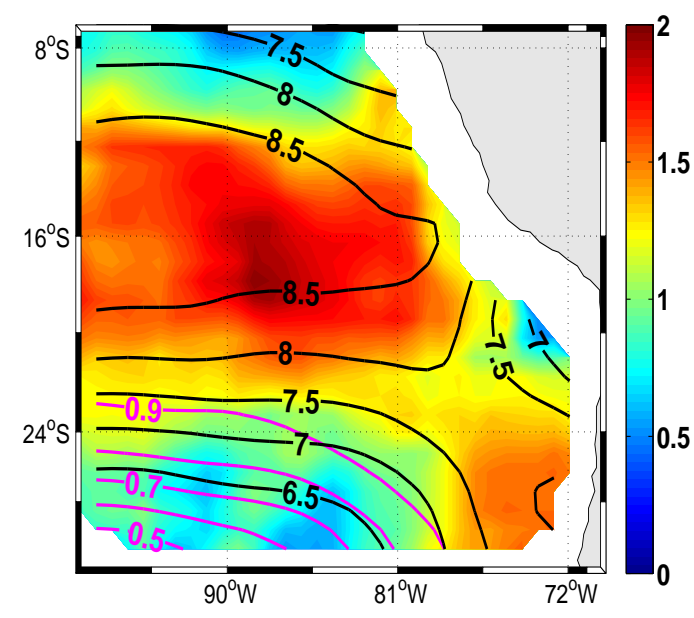

Fig. 8: RC between WS and SST anomalies (colored, $10^{-2} \mathrm{~N} \mathrm{~m}^{-2}{ }^{\circ} \mathrm{C}^{-1}$ ) in the CPLM simulation for winter 2007. Wind steadiness is indicated by magenta contours with contour interval of 0.1 . Wind speed $\left(\mathrm{m} \mathrm{s}^{-1}\right)$ is indicated by black contours, contours interval is $0.5 \mathrm{~m} \mathrm{~s}^{-1}$. 
(a)

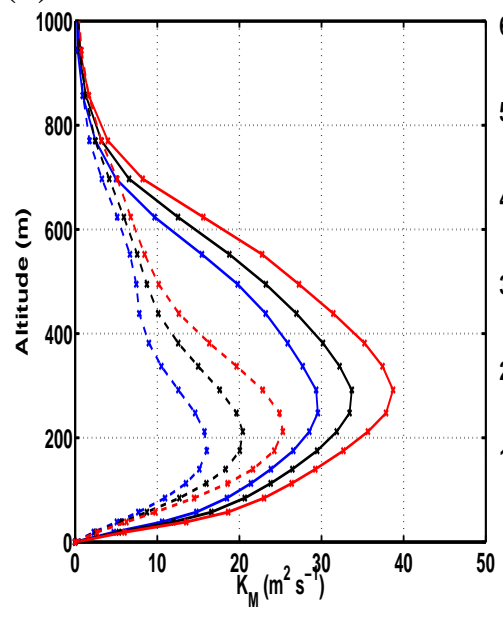

(b)

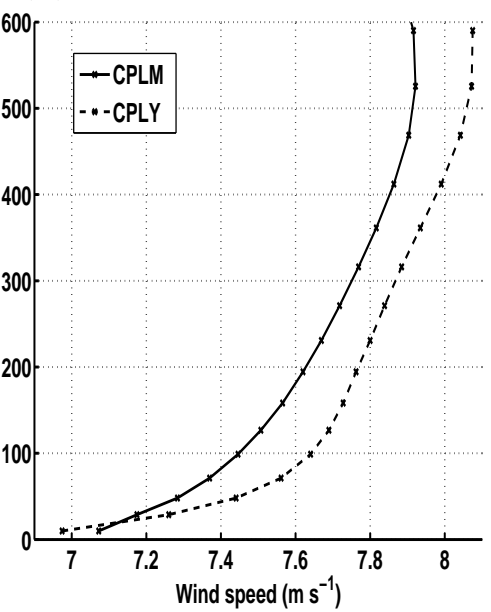

(c)

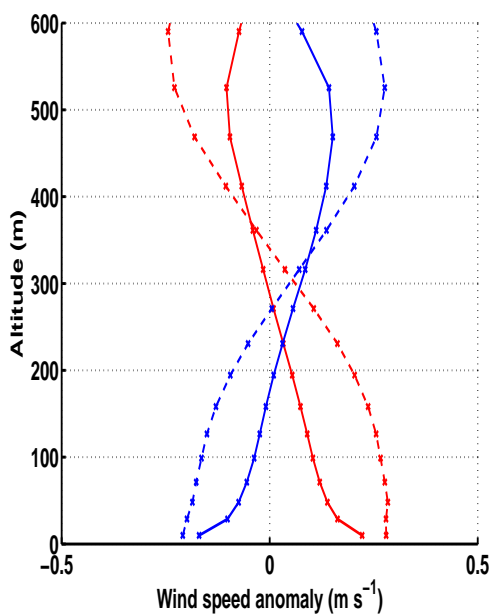

Fig. 9: Vertical profiles computed using time-averaged fields over July 2007 in the Peru region for CPLM (plain lines) and CPLY (dotted lines); (a) mixing coefficient $K_{M}\left(\mathrm{~m}^{2} \mathrm{~s}^{-1}\right)$ mean profile (black), profile above warm SST anomalies (red) and profile above cold SST anomalies (blue). Only anomalies with absolute value larger than $0.1{ }^{\circ} \mathrm{C}$ are considered; (b) mean wind speed profile (m $\left.\mathrm{s}^{-1}\right)$. (c) Wind speed anomalies $\left(\mathrm{m} \mathrm{s}^{-1}\right.$ ) profiles above warm SST anomalies (red) and cold SST anomalies (blue). The vertical axes of the wind speed anomalies were previously rescaled (see Sec. 2.4)

\section{(a)}

(b)
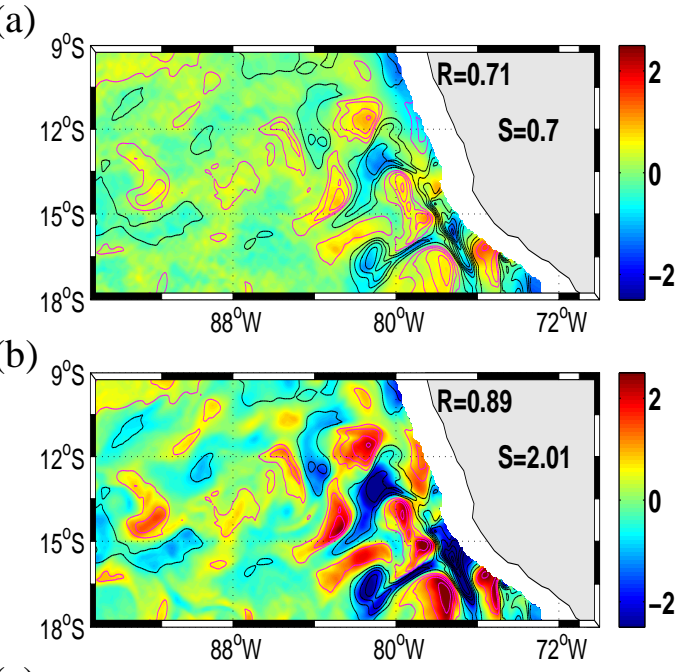

(c)

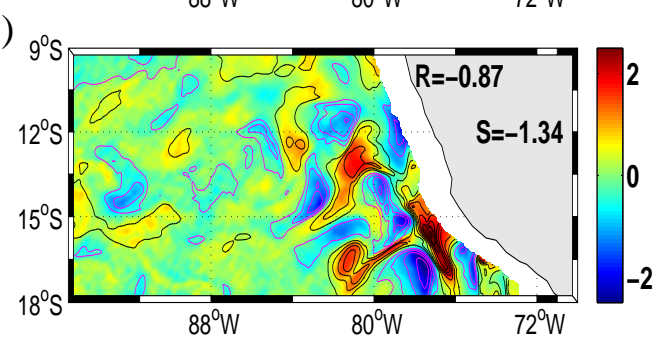

Fig. 10: (a) Downwind turbulent stress anomalies $\tau_{1}^{\prime}\left(10^{-2} \mathrm{~N} \mathrm{~m}^{-2}\right)$ at $20 \mathrm{~m}$ height. $\tau_{1}^{\prime}$ is decomposed into $\tau_{a}^{\prime}$ and $\tau_{b}^{\prime}$ with $\tau_{a}^{\prime}$ related to the mixing coefficient $K_{M}$ anomalies and $\tau_{b}^{\prime}$ proportional to the wind speed shear anomalies; (b) $\tau_{a}^{\prime}\left(10^{-2} \mathrm{~N} \mathrm{~m}^{-2}\right)$ at $20 \mathrm{~m}$. (c) $\tau_{b}^{\prime}\left(10^{-2} \mathrm{~N} \mathrm{~m}^{-2}\right)$ at $20 \mathrm{~m}$. SST anomalies are indicated by contours (black for negative anomalies, magenta for positive anomalies), contour interval is $0.25^{\circ} \mathrm{C}$. Correlation (R) and Regression Coefficient (RC, in $10^{-2} \mathrm{~N} \mathrm{~m}^{-2}{ }^{\circ} \mathrm{C}^{-1}$ ) between SST and stress anomalies are indicated. 
(a)

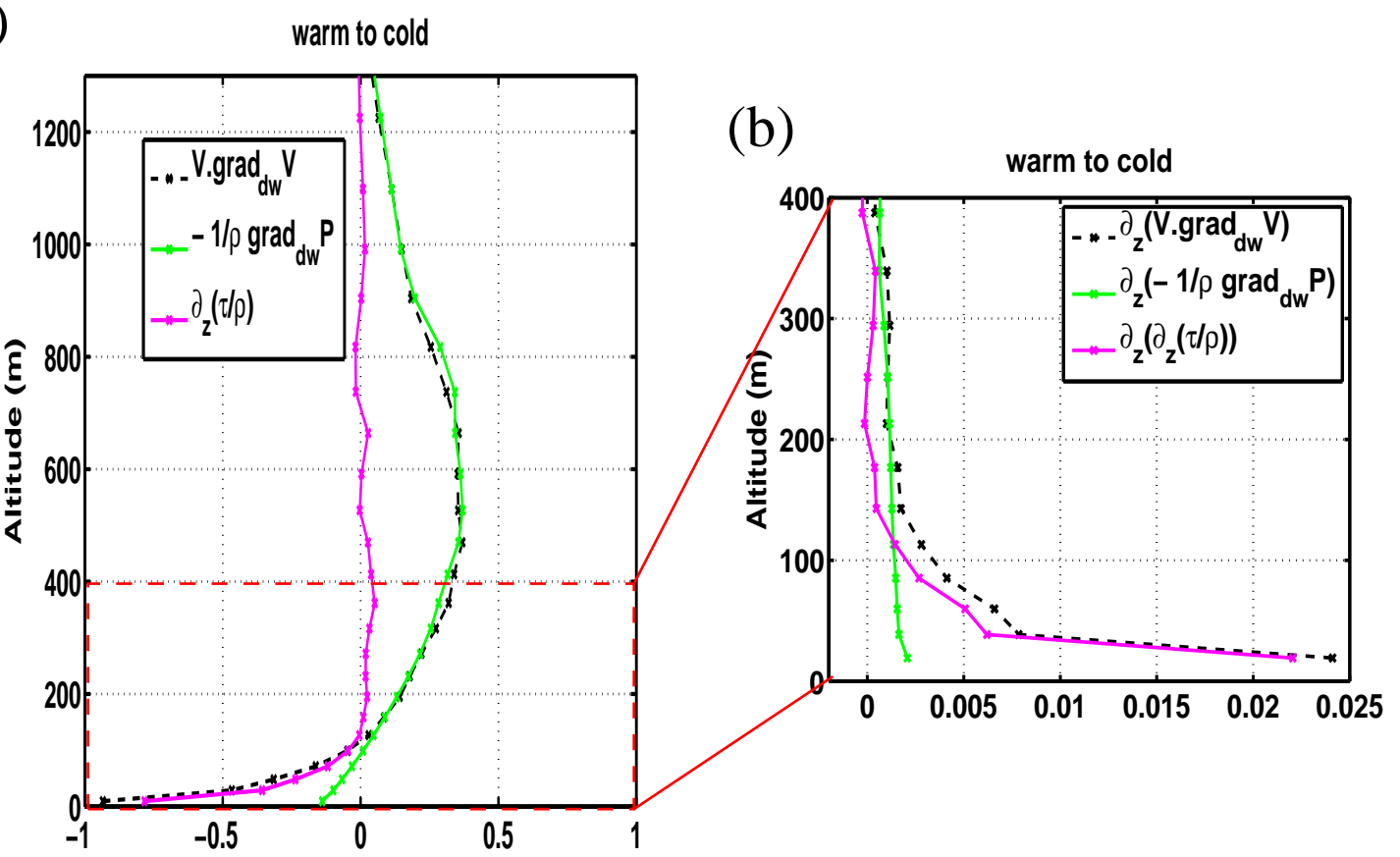

(c)

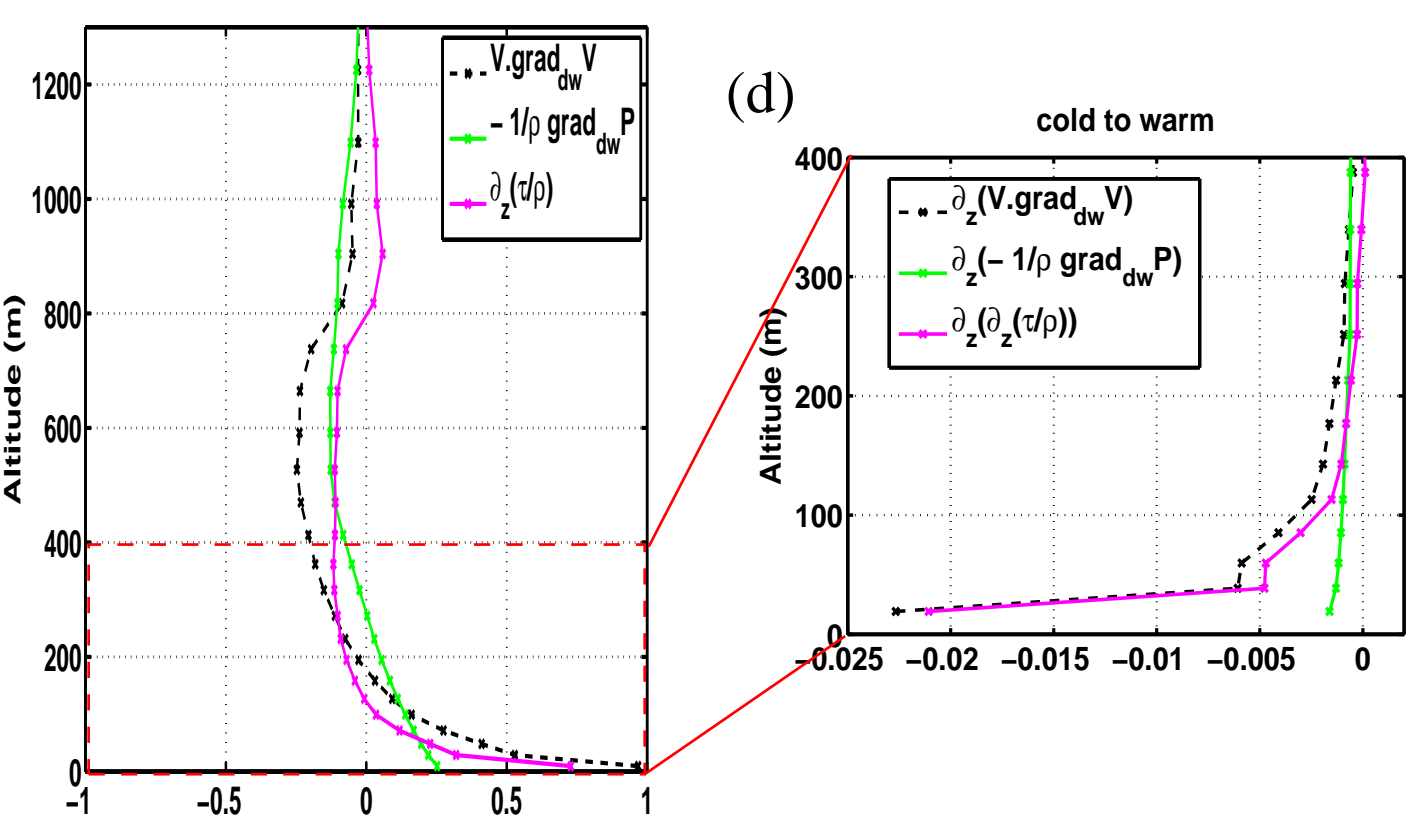

Fig. 11: Composite terms of the downwind momentum balance anomaly above downwind SST gradient anomalies with intensity larger than $2.10^{-5}{ }^{\circ} \mathrm{C} \mathrm{m}^{-1}$. Balance is for July 2007 in CPLM over the Peru region. (a) Composite terms above negative downwind gradient anomalies (warm to cold transition). Downwind momentum balance anomalies (eq. (10)) terms are: Lagrangian acceleration of the air parcel along the streamline (black), momentum turbulent mixing (magenta), pressure term (green), units are $10^{5} \mathrm{~m}^{2} \mathrm{~s}^{-2}$ ${ }^{\circ} \mathrm{C}^{-1}$. Terms have been normalized by the downwind gradient anomalies intensity. (b) vertical shear of the profiles shown in (a), in $10^{5} \mathrm{~m} \mathrm{~s}^{-2}{ }^{\circ} \mathrm{C}^{-1}$. (c) same as (a) but for positive downwind gradient anomalies (cold to warm transition). (d) vertical shear of the profile shown in (b) 
(a)

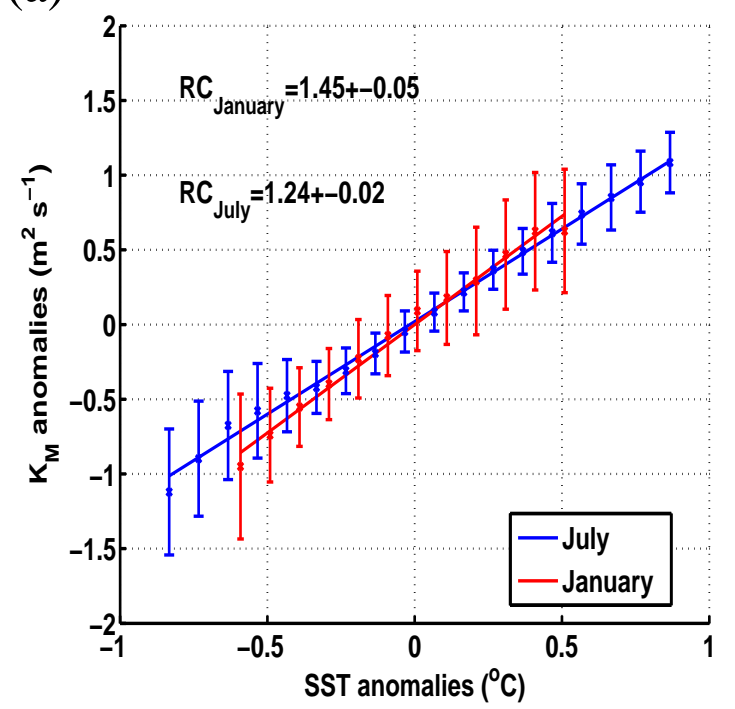

(b)

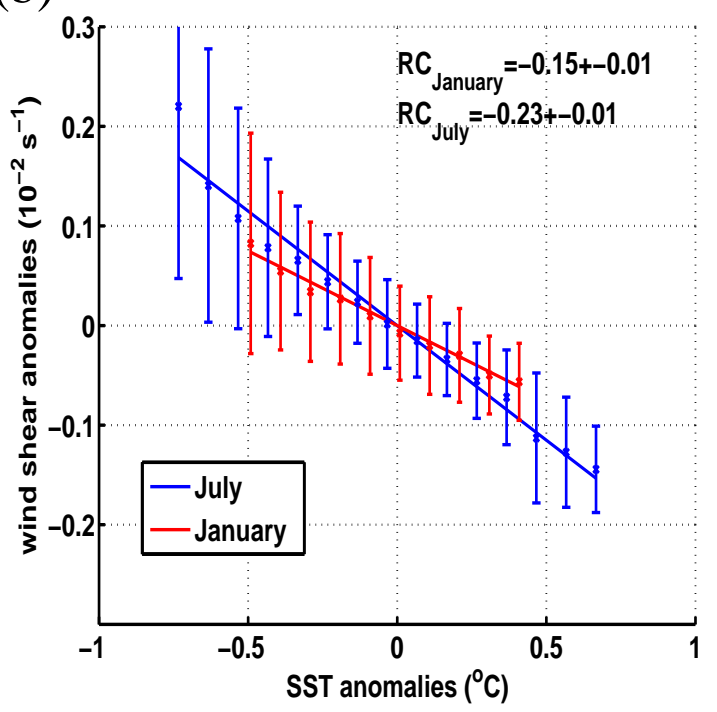

Fig. 12: Binned scatterplot of (a) $K_{M}\left(\mathrm{~m}^{2} \mathrm{~s}^{-1}\right)$ and (b) the intensity of $\partial_{z} \overrightarrow{v^{\prime}}$ anomalies at $20 \mathrm{~m}\left(\mathrm{~s}^{-1}\right)$ with respect to the SST anomalies $\left({ }^{\circ} \mathrm{C}\right)$. Red line is for January and blue line is for July. The RC are also indicated.

(a)

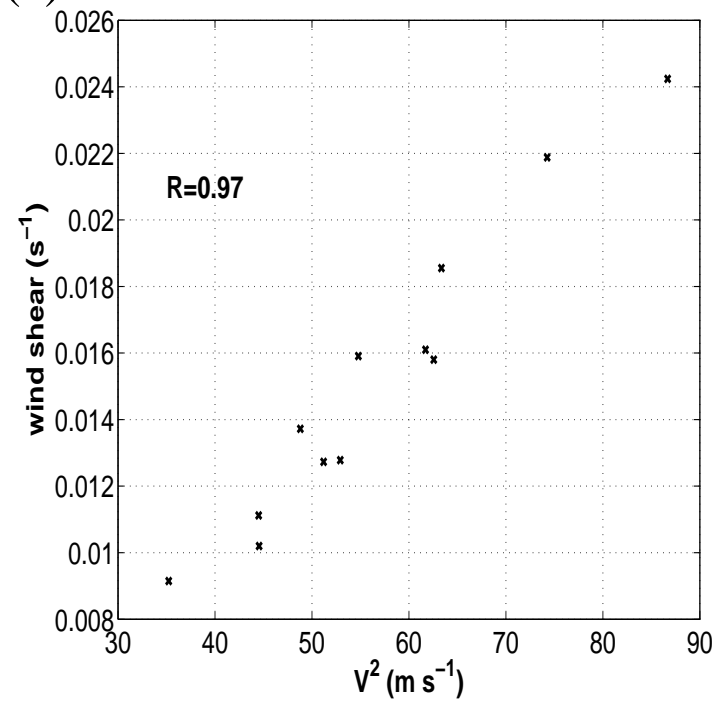

(b)

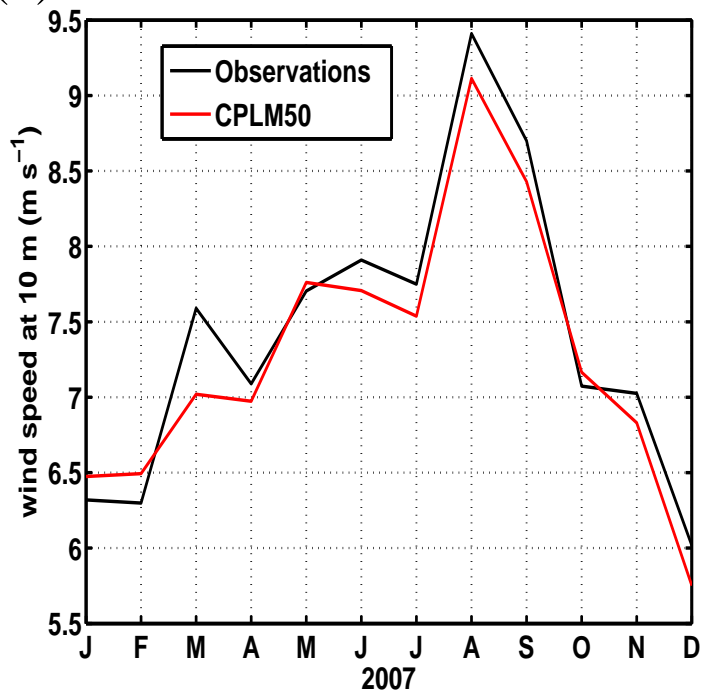

Fig. 13: (a) Scatterplot of the large-scale wind shear $\left\|\overline{\partial_{z}} \vec{v}\right\|$ at $20 \mathrm{~m}$ with respect to the wind speed at $10 \mathrm{~m}$. Scatterplot values are monthly means spatially averaged over the Peru domain; (b) Seasonal cycle of the wind speed at $10 \mathrm{~m}$, spatially averaged over the Peru domain. 
(a)

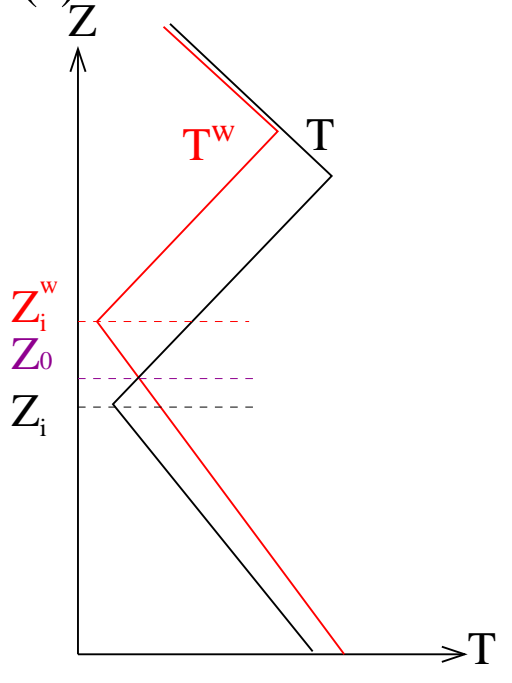

(b)

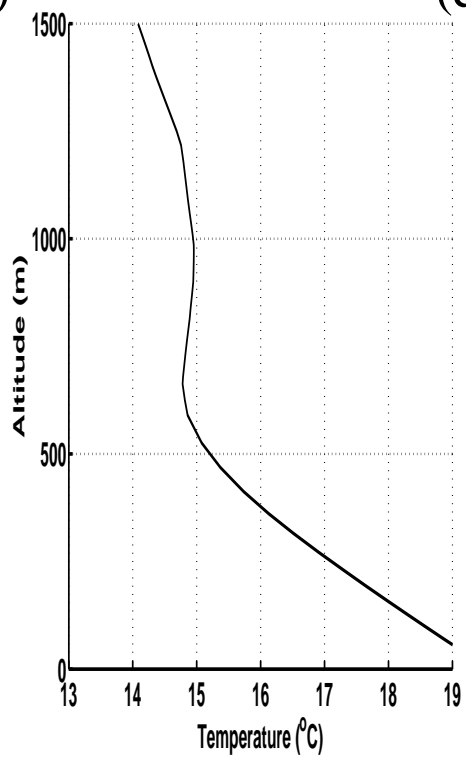

(c)

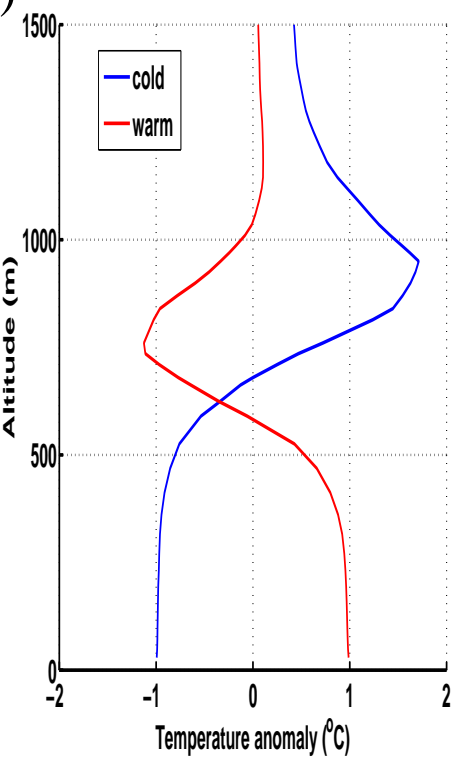

Fig. 14: (a) Scheme of a mean air temperature profile ( $T$, black line) and the corresponding composites above warm SST anomalies $\left(T^{w}\right.$, red line) in a region presenting a strong temperature inversion. Inversion height is $Z_{i}$ for the $T$ profile and $Z_{i}^{c}$ for the $T_{c}$ profile. Scheme is adapted from Hashizume et al (2002). The symetric situation occurs for the cold composite (not shown) (b) mean temperature profile $\left({ }^{\circ} \mathrm{C}\right.$ ) over the Peru region during July 2007. (c) Composites of air temperature anomalies above $10 \mathrm{~m}$ air temperature warm (red) and cold (blue) anomalies. Only anomalies with an absolute value larger than $0.5^{\circ} \mathrm{C}$ are considered. $\mathrm{Z}$-axes of each profiles is first normalized (see Sec. 2.4). Profiles are also normalized by the $10 \mathrm{~m}$ air temperature anomalies 